\title{
Two Type III Secretion System Effectors from Ralstonia solanacearum GMI1000 Determine Host-Range Specificity on Tobacco
}

\author{
Marie Poueymiro, Sébastien Cunnac, Patrick Barberis, Laurent Deslandes, Nemo Peeters, \\ Anne-Claire Cazale-Noel, Christian Boucher, and Stéphane Genin
}

Laboratoire des Interactions Plantes Micro-organismes (LIPM), UMR CNRS-INRA 2594/441, F-31320 Castanet Tolosan, France

Submitted 10 November 2008. Accepted 20 January 2009.

\begin{abstract}
The model pathogen Ralstonia solanacearum GMI1000 is the causal agent of the bacterial wilt disease that attacks many solanaceous plants and other hosts but not tobacco (Nicotiana spp.). We found that two type III secretion system effector genes, avrA and popP1, are limiting the host range of strain GMI1000 on at least three tobacco species (N. tabacum, N. benthamiana, and N. glutinosa). Both effectors elicit the hypersensitive response (HR) on these tobacco species, although in different manners; AvrA is the major determinant recognized by $N$. tabacum and $N$. benthamiana, while PopP1 appears to be the major HR elicitor on $N$. glutinosa. Only the double inactivation of the avrA and popP1 genes allowed GMI1000 to wilt tobacco plants, thus showing that GMI1000 intrinsically possesses the functions necessary to wilt tobacco plants. A focused analysis on AvrA revealed that the first $58 \mathrm{~N}$-terminal amino acids are sufficient to direct its injection into plant cells. We identified a hypervariable region in avrA, which contains variable numbers of tandem repeats (VNTR), each composed of 12 base pairs. We show that an 18-amino acid region in which the VNTR insertion occurs is an important domain involved in HR elicitation on $N$. benthamiana. avrA appears to be the target of various DNA insertions or mobile elements that probably allow $R$. solanacearum to evade the recognition and defense responses of tobacco.
\end{abstract}

The interaction between a microbial pathogen and its plant host is a complex multistep process. To successfully infect a plant, the pathogen first has to be able to penetrate and colonize host tissues and overcome active plant defense responses to finally induce the set of events that leads to disease symptoms. Plant lines of defense involve preformed physical or chemical barriers as well as inducible responses like cell-wall strengthening, release of antimicrobial compounds, or a rapid localized and programmed cell death at sites of infection known as the hypersensitive response (HR) (de Wit 2007; Klement 1963; Mur et al. 2008). Induction of the HR is observed at the

Marie Poueymiro and Sébastien Cunnac contributed equally to this work.

Current address for S. Cunnac: Department of Plant Pathology and PlantMicrobe Biology, Cornell University, Ithaca, NY 14853, U.S.A.

Corresponding author: Stéphane Genin; E-mail: sgenin@ toulouse.inra.fr

* The $\boldsymbol{e}$-Xtra logo stands for "electronic extra" and indicates that two supplemental tables and one supplemental figure are published online and that Figures 1, 3, 5, and 10 appear in color online. intraspecific level in certain plant lines or cultivars not susceptible to individual pathogen strains or races that are otherwise pathogenic to representatives of that species. Gene-for-gene relationship models account for such incompatible interactions occurring when the plant possesses a resistance gene product that perceives the presence or the activity of the matching avirulence ( $a v r)$ gene product from the pathogen (Flor 1955; Jones and Dangl 2006). Hence, HR is the consequence of specific recognition of determinants of the pathogen, and many reports over the last decades have documented the existence of such bacterial 'avirulence' factors, which are, in most of the cases, products of type III secretion system (T3SS) effector genes (Block et al. 2008; Grant et al. 2006; Leach and White 1996).

It is established that different plant species can recognize the same $a v r$ gene product (Dangl et al. 1992; Whalen et al. 1991). For example, avrXv4 controls the incompatibility of Xanthomonas campestris pv. vesicatoria not only on the wild tomato relative Lycopersicon pennellii but also on the nonhost Nicotiana benthamiana (Roden et al. 2004). Such observations provided a basis to the view that $a v r$ gene products elicit defense responses both in the context of host and nonhost resistance, thereby contributing to restrict the plant host range of a bacterial pathogen. In some other cases, additional factors superimpose upon the avr gene to determine compatibility; reports have shown that inactivation of some of the $a v r$ gene eliminates the HR but does not enable the strains to cause disease symptoms on the same host (Leach and White 1996). There are paradoxical observations showing that $a v r$ genes were maintained in bacterial populations despite their negative effect in restricting host range. Two possible explanations are that several $a v r$ genes are required for pathogen fitness (Kearney and Staskawicz 1990; Lim and Kunkel 2005; Lorang et al. 1994; Losada et al. 2004; Ritter and Dangl 1995; Swarup et al. 1992) or that HR-inducing ability of certain effectors is suppressed by other effectors (Grant et al. 2006; Zhou and Chai 2008).

Our research focuses on pathogenicity determinants of Ralstonia solanacearum, the causal agent of bacterial wilt disease, a source of major yield losses worldwide (Hayward 1991). $R$. solanacearum has an uncommonly wide host range extending across several plant families. The bacterium survives in the soil, enters the plant root system, and gains access to systemic invasion by colonizing the xylem vessels. As in many other bacterial pathogens, a major determinant of $R$. solanacearum's pathogenicity is its T3SS, encoded by hrp genes (Boucher et al. 1987; Van Gijsegem et al. 2002). The genome of the model strain GMI1000 has been sequenced, paving the way for in silico analysis and functional genomic approaches (Cunnac et 
al. 2004; Genin and Boucher 2004; Salanoubat et al. 2002; Valls et al. 2006). More than 70 candidate T3SS effector genes were identified in this strain, and a dozen of them have been demonstrated to be translocated into plant cells through the T3SS (Angot et al. 2006; Cunnac et al. 2004).

Several determinants specifying the host range of the bacterium have been already identified and, to date, all these determinants were shown to be encoded by T3SS-dependent effector genes. In a pioneering study, the avrA locus was identified in strain AW1 as a 2-kb DNA fragment sufficient to condition incompatibility on tobacco at the species level (Carney and Denny 1990). N. tabacum is considered as a nonhost plant for most $R$. solanacearum strains, and leaf infiltration of the bacterium results in the HR, manifested by a rapid necrosis localized to the inoculation site and expression of various HR-associated molecular markers (Tronchet et al. 2001). In recent years, additional T3SS effector genes from strain GMI1000 were found to encode avirulence determinants such as popPl, which specifies avirulence toward some petunia lines (Lavie et al. 2002), and popP2, which encodes the effector protein recognized by the Arabidopsis resistance gene product RRS1-R (Deslandes et al. 2003). Contrary to avirulence genes, another GMI1000 T3SS effector was recently found to extend the host range of the bacterium, since the GALA7 effector was shown to be specifically required for compatibility on the host plant Medicago truncatula (Angot et al. 2006).

The objective of this work was to study the factors restricting the pathogenicity of strain GMI1000 on tobacco. We found that, in addition to AvrA, a second effector gene product encoded by popP1 is also involved in HR elicitation on different Nicotiana species. Remarkably, the double inactivation of the $a v r A$ and popPl genes restored the pathogenicity of GMI1000 on tobacco plants. Since the functional characterization of PopP1 has already been performed (Lavie et al. 2002), we focused our analysis on the study of AvrA. We mapped the T3SS translocation signals within AvrA and analyzed the role of some $h r p$ cluster genes in translocation of this protein. Finally, we identified a hypervariable domain in AvrA, which was found to result from the presence of a variable number of tandem repeats within the $a v r A$ coding sequence, and we provide evidence that these DNA insertions occur within a domain involved in HR elicitation.

\section{RESULTS}

\section{Identification of avrA and popPI}

as the major determinants responsible

for HR elicitation on Nicotiana tabacum.

We evaluated the ability of more than 60 candidate type III effector mutant strains generated in strain GMI1000 (Cunnac et al. 2004; Occhialini et al. 2005) to elicit the HR on the nonhost Nicotiana tabacum cv. Bottom special by infiltration at the rate of $10^{8}$ cells $/ \mathrm{ml}$ in the leaf parenchyma. All but one strain elicited a typical HR response indistinguishable from the confluent necrotic lesions observed $24 \mathrm{~h}$ postinfiltration of the wild-type strain. The mutant strain GRS99, carrying a disruption of the $h r p B$-regulated gene avrA (RSc0608) (Cunnac et al. 2004; Robertson et al. 2004), was strongly altered in its ability to induce the HR (Fig. 1). Up to $24 \mathrm{~h}$ after inoculation, the HR phenotype of strain GRS99 was null and indistinguishable from the GMI1694 ( $h r p$ mutant) phenotype. However, after 2 days, leaf areas inoculated with GRS99 exhibited some restricted necrotic spots while areas inoculated with the hrp mutant strain GMI1694 remained unaffected. Leaf infiltration at lower inoculum densities $\left(10^{7}\right.$ cells $\left./ \mathrm{ml}\right)$ resulted in a complete HR-negative phenotype for GRS99, in contrast to the wildtype strain, which remained able to elicit a normal HR at the same bacterial density (data not shown).

The appearance of necrotic spots (that ended in HR $96 \mathrm{~h}$ postinfiltration) in the infiltrated area with the $a v r A$ mutant at a

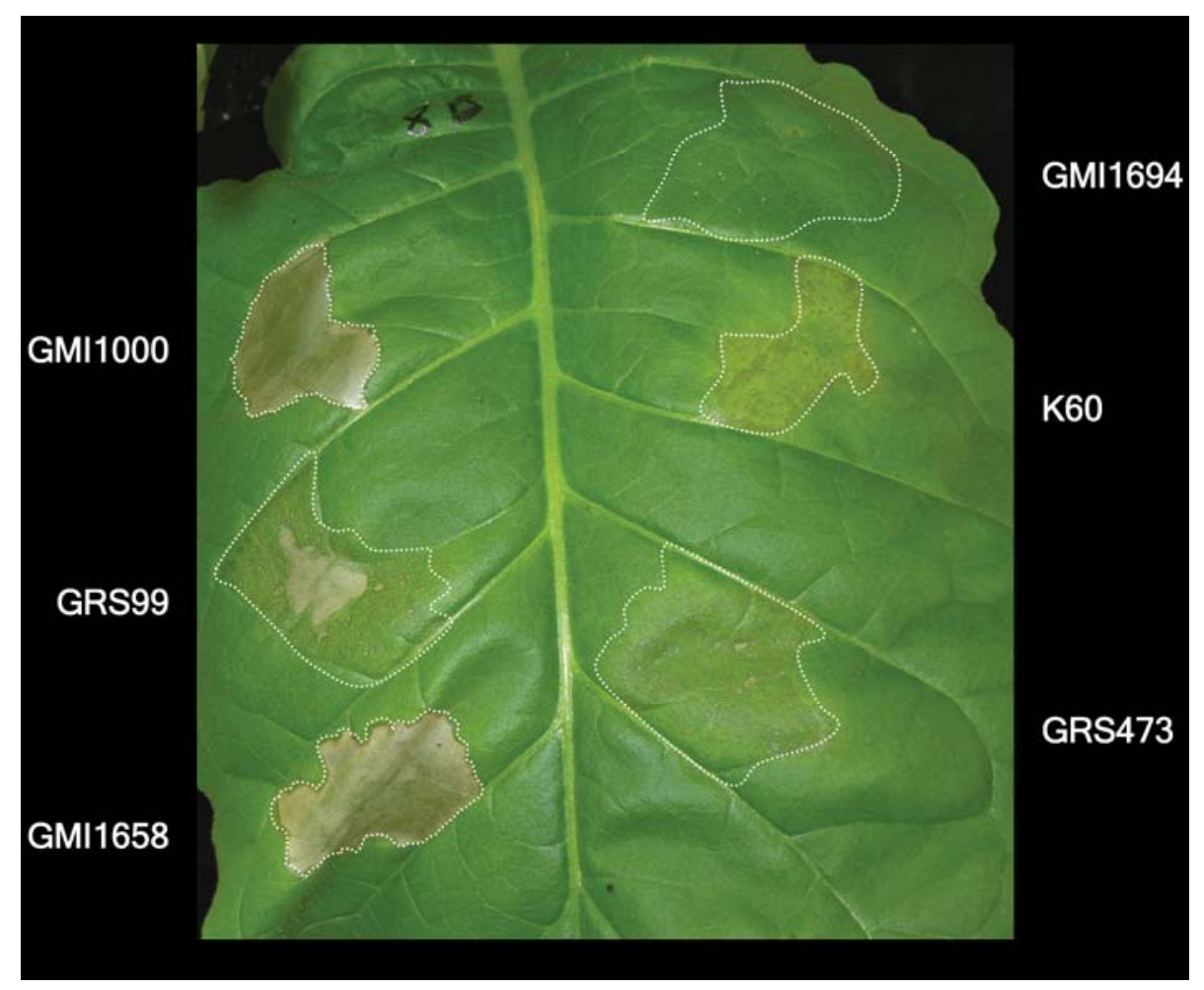

Fig. 1. avrA and popPl are both involved in hypersensitive response elicitation on Nicotiana tabacum. Tobacco leaves were infiltrated with bacterial suspensions at $10^{8} \mathrm{CFU} / \mathrm{ml}$ of the $a v r A$ mutant GRS99, the popP1 mutant GMI1658, the avrA popP1 mutant GRS473, the hrp mutant GMI1694, and the wild-type strains GMI1000 and K60. Picture was taken $48 \mathrm{~h}$ postinfiltration. The dotted lines represent the infiltrated areas. 
rate of $10^{8}$ cells $/ \mathrm{ml}$ suggested that an additional factor exerts a weak HR activity on tobacco leaf cells. Because this residual HR cannot be observed with the hrp mutant strain GMI1694, we reasoned that this phenotype is due to the recognition of other type III effectors by the plant surveillance system under high inoculum conditions (i.e., less efficiently than AvrA). We therefore generated an $a v r A$ mutation in all the type III effector mutant strains derived from GMI1000, resulting in a collection of double mutants carrying a disruption in avrA and each of the other effector genes. We then performed a second screening for HR elicitation abilities on $N$. tabacum leaves by infiltrating each of these double mutant strains at the rate of $10^{8}$ cells $/ \mathrm{ml}$. All but one strain elicited the same reaction (i.e., residual HR) as the single avrA mutant strain. We found that only the double mutant strain GRS473, carrying a disruption in both $a v r A$ and popP1, elicited no HR response after 2 days in a manner comparable to the hrp mutant GMI1694. This absence of HR was also observed with strain K60, a typical pathogenic strain isolated from tobacco (Kelman and Person 1961) (Fig. 1). The popPl mutant strain elicited an HR comparable to that of the wild-type strain. This indicates that $a v r A$ and popPl are jointly involved in $\mathrm{HR}$ elicitation of strain GMI1000 on N. tabacum, although the contribution of AvrA appears more important than that of PopP1 on this species.

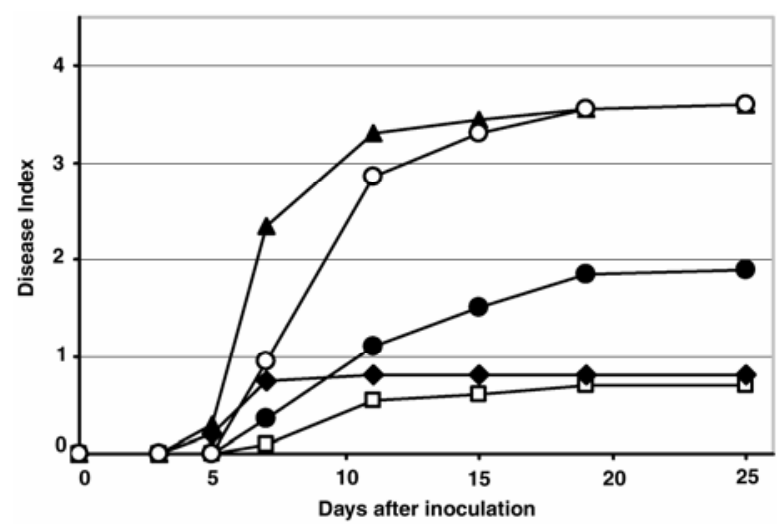

Fig. 2. The avrA popPl double mutant is fully pathogenic on Nicotiana tabacum. Evolution of the average disease index over time of tobacco plants inoculated with the avrA popP1 mutant GRS473 ( $\mathbf{\Delta})$, the avrA mutant GRS99 $(\bullet)$, the popP1 mutant GMI1658 $(\bullet)$, and the wild-type strains GMI1000 $(\square)$ and K60 (O). Each point represents the mean disease index of three individual experiments, each containing 16 plants per treatment.
Cumulative disruption of popP1 and avrA renders GMI1000 able to wilt $N$. tabacum.

The initial characterization of $a v r A$ in strain AW1 indicated that pathogenicity on tobacco was not acquired when this gene was inactivated (Carney and Denny 1990). Using the soil drenching inoculation procedure, we found that both the avrA and the popPl single mutant strains did not caused disease symptoms and behaved as GMI1000 (Fig. 2). Although the GRS99 strain (avrA mutant) appeared to be slightly more virulent, statistical analyses of the data did not confirm the significance of the difference observed between GMI1000 and GRS99. However, contrary to these single mutant strains, the double mutant strain GRS473 (avrA popPl) acquired the ability to wilt tobacco plants similarly to the pathogenic isolate K60. The finding that disruption of avrA and popP1 restored full pathogencity on $N$. tabacum demonstrates that these two genes are the major avirulence determinants controlling compatibility of GMI1000 on this plant species.

\section{Differential contribution of avrA and popP1 \\ to HR elicitation on different Nicotiana species.}

The HR-eliciting activity of GMI1000 and the popPl and avrA mutant strains was also tested on two other Nicotiana species, $N$. benthamiana and $N$. glutinosa. On $N$. benthamiana, the response is mainly dependent on the presence of a functional avrA gene, similarly to what was observed in N. tabacum, although the appearance of the HR is slightly delayed with a residual $\mathrm{HR}$ appearing up to 48 to $72 \mathrm{~h}$ postinoculation. At 48 $\mathrm{h}$ after inoculation of GMI1000 or GMI1658, a HR response developed, while the avrA popP1 double mutant produced no $\mathrm{HR}$ and induced a watersoaking-like reaction (Fig. 3A).

In contrast to $R$. solanacearum AW1, strain GMI1000 has a HR-positive phenotype on $N$. glutinosa (Carney and Denny 1990). As shown in Figure 3, N. glutinosa leaves responded identically to infiltration with GRS99 and GMI1000 strains, indicating that, on this species, avrA is dispensable for the appearance of HR. On the contrary, the strain GMI1658 (popPl mutant) was found to be delayed in its HR-eliciting activity on this tobacco species, while the GRS473 avrA popPl double mutant strain induced no HR (Fig. 3B). At 3 days after inoculation, the area infiltrated with GRS473 started to evolve into disease symptoms similarly to the pathogenic tobacco strain K60 (Fig. 3C).

Finally, pathogenicity assays using $N$. benthamiana and $N$. glutinosa plants also confirmed that the GRS473 double mutant strain was also fully virulent on these two tobacco species, con-
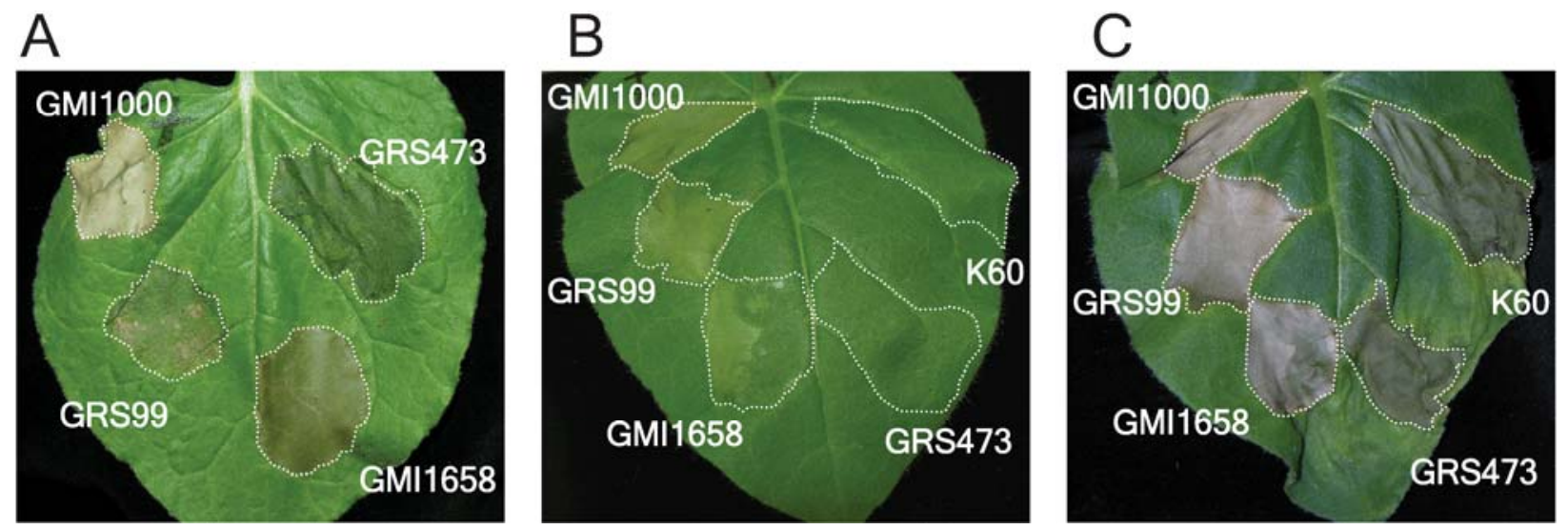

Fig. 3. Differential behavior of the avrA and popP1 mutant strains on Nicotiana benthamiana and $N$. glutinosa leaves. Tobacco leaves were infiltrated with bacterial suspensions at $10^{8} \mathrm{CFU} / \mathrm{ml}$ of the avrA mutant GRS99, the popP1 mutant GMI1658, the avrA popP1 mutant GRS473, and the wild-type strains GMI1000 and K60. A, Phenotypes observed on N. benthamiana 3 days after infiltration. B and C, Phenotypes observed on N. glutinosa 1 and 3 days after infiltration, respectively. The dotted lines represent the infiltrated areas. 
trary to the wild-type GMI1000 strain (Fig. 4). Altogether, these results indicate that AvrA and PopP1 are both responsible in restricting the host range of GMI1000 on different Nicotiana species, although they differ in their respective contribution to the HR responses; PopP1 is the major avirulence factor on $N$. glutinosa, whereas AvrA is the major determinant on N. tabacum and N. benthamiana.

In planta expression of AvrA and PopP1 avirulence proteins triggers HR in different Nicotiana species.

In order to prove that the AvrA and PopP1 effectors alone were sufficient for elicitation of the HR, the proteins were expressed within plant cells, using the Agrobacterium-mediated transient expression assay. Tobacco leaves were infiltrated with A. tumefaciens strains containing pMP25 (a Cauliflower mosaic virus [CaMV] 2x35S:avrA construct) or pMP103 (a CaMV 2x35S:popP1-CFP fusion). Within 48 to $72 \mathrm{~h}$, we observed, with both constructs, that the infiltrated areas of the three tobacco species tested ( $N$. tabacum, $N$. benthamiana, and N. glutinosa) exhibited a typical HR-like response (Fig. 5), showing that both PopP1 and AvrA are sufficient to trigger an intracellular recognition event within tobacco cells after Agrobacterium-mediated delivery. This response was specific to PopP1 and AvrA, since no response was observed after expression of several other GMI1000 effectors such as GALA6.

\section{The first 58 N-terminal amino acids of AvrA} are sufficient to direct the secretion and injection of a Cya reporter fusion into plant cells.

The translocation assay based on the calmodulin-dependent adenylate cyclase domain $\left(\mathrm{CyaA}^{\prime}\right)$ of the Bordetella pertussis cyclolysin (Casper-Lindley et al. 2002; Sory and Cornelis 1994) was used to prove that AvrA is injected into plant cells through the T3SS. Four constructions were generated containing upstream avrA transcription regulatory regions, followed by an initiation codon or the first 30, 58, or 99 codons of avrA in translational fusion with the $c y a A^{\prime}$ gene, resulting in plasmids pSC177 (AvrA $\left.{ }^{1-1}-\mathrm{CyaA}^{\prime}\right), \mathrm{pSC} 178\left(\mathrm{AvrA}^{1-30}-\mathrm{CyaA}^{\prime}\right)$, pSC179 (AvrA $\left.{ }^{1-58}-\mathrm{CyaA}^{\prime}\right)$, and $\mathrm{pSC} 163\left(\mathrm{AvrA}^{1-99}-\mathrm{CyaA}^{\prime}\right)$ as depicted in Figure 6A. These plasmids were introduced into strain GMI1000 and the hrp secretion mutant strain GMI1402 (Van Gijsegem et al. 1995). To test the secretion of AvrA$\mathrm{CyaA}^{\prime}$ hybrids in the extracellular medium, concentrated culture supernatants of the different strains were subjected to Western blot analysis. The recombinant proteins were produced at comparable levels (Fig. 6B, IN). On the immunoblot obtained with concentrated supernatant preparations (Fig. 6B, OUT), the AvrA $^{1-99}-\mathrm{CyaA}^{\prime}$ is detected when produced in the wild-type

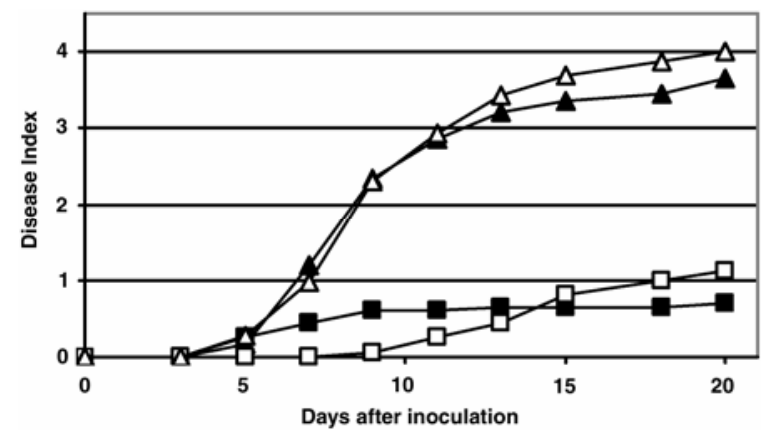

Fig. 4. Virulence test of the avrA popP1 double mutant strain (GRS473) on Nicotiana benthamiana and $N$. glutinosa. Progression of the average wilting symptoms over 20 days on $N$. benthamiana (filled symbols) and $N$. glutinosa (open symbols) inoculated with GRS473 (triangles) and with GMI1000 (squares). Each point represents the mean disease index of three individual experiments, each containing 16 plants per treatment. genetic background but not in the hrp background, showing that AvrA ${ }^{1-99}-C_{y a A^{\prime}}$ is secreted in the extracellular medium in an $h r p$-dependent fashion. AvrA ${ }^{1-58}-\mathrm{CyaA}^{\prime}$ is also detected in the supernatant but no signal is detected for AvrA ${ }^{1-30}-\mathrm{CyaA}^{\prime}$ and AvrA $^{1-1}-\mathrm{CyaA}^{\prime}$ although these fusions can be detected in the cellular fraction. This suggests that the two shortest AvrA $\mathrm{N}$-terminal sequences could not direct efficient secretion of the reporter fusion.

Next, we verified that the chimeric AvrA-CyaA' fusions have in vitro calmodulin-dependent adenylate cyclase activity. In extracts from bacterial strains expressing the different

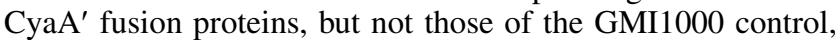
the adenylate cyclase activity was at least 40 times higher in the presence of calmodulin (Fig. 6C). These data demonstrate that the hybrid proteins were functional and that their activity was strictly calmodulin dependent. We then checked the translocation ability of the AvrA ${ }^{1-99}-\mathrm{CyaA}^{\prime}$ fusion expressed from the native $a v r A$ promoter. Compared with GMI1402/pSC163 or GMI1000 alone, GMI1000/pSC163 induced a strong increase of cyclic AMP (cAMP) concentration in Arabidopsis cells, thus supporting the conclusion that $\mathrm{AvrA}^{1-99}-\mathrm{CyaA}^{\prime}$ is translocated into plant cells in an Hrp-dependent manner. The AvrA ${ }^{1-}$ ${ }^{58}$ CyaA $^{\prime}$ also appears to be translocated, although the cAMP levels produced by GMI1000/pSC179 were slightly reduced in comparison with GMI1000/pSC163. In contrast, Arabidopsis cells cultivated with GMI1000/pSC178 or GMI1000/pSC177 accumulated cAMP to background levels, showing that the first 30 amino acids of AvrA are unable to direct injection of CyaA'.

Finally, we tested the ability to translocate AvrA of four hrp mutants carrying nonpolar mutations in the $h r p D, h r p H, h r p J$, and $h p a P$ genes and displaying delayed or reduced HR phenotypes (Van Gijsegem et al. 2002). These four hrp mutants in-
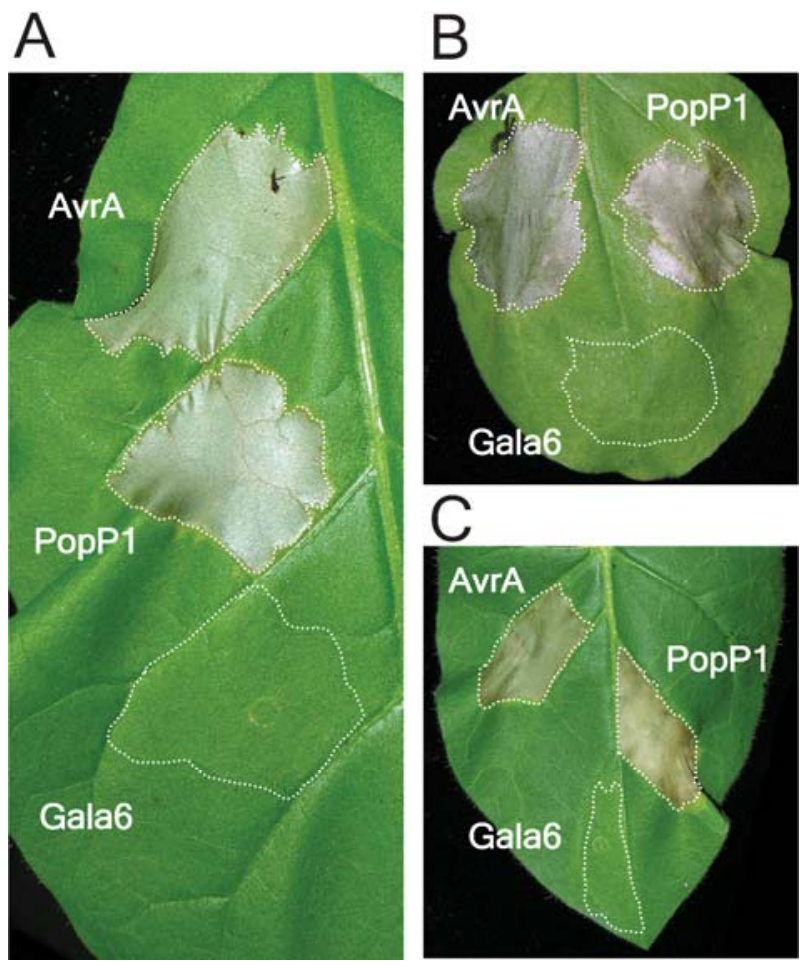

Fig. 5. Hypersensitive response elicitation induced by the Agrobacteriummediated transient expression of avrA and popP1 on tobacco species. A, Leaves of Nicotiana tabacum, B, N. benthamiana, and C, N. glutinosa were infiltrated with Agrobacterium tumefaciens strains carrying an avrA or popP1 or GALA6 gene. Pictures were taken 5 days after agroinfiltration. The dotted lines represent the infiltrated areas. 
jected the reporter fusion from pSC163 (AvrA $\left.{ }^{1-99}-\mathrm{CyaA}^{\prime}\right)$ at low efficiency (Supplementary Fig. 1), since detected cAMP accumulation in tobacco leaves was about half that induced by GMI1000. The targeting of AvrA ${ }^{1-99}{ }_{-} \mathrm{CyaA}^{\prime}$ into plant cells was more severely impaired in the hrpJ mutant, as this strain induced cAMP values approximately sixfold lower than those of GMI1000.

avrA belongs to a multicistronic operon regulated by $h r p B$.

Immediately downstream of a $v r A$ are four genes transcribed in the same orientation (Fig. 7). The definition of the transcriptomic profiling of an $h r p B$ mutant strain revealed that, as with $a v r A$, expression of the $R S c 0609$ gene was also $h r p B$-dependent (Occhialini et al. 2005). The regulation pattern of the $R S c 0609$ through $R S c 0613$ genes has been followed in several independent transcriptomic profiling experiments using either $h r p$ regulatory mutants or strains overexpressing the $h r p B$ or $h r p G$ regulatory genes. Using standard criteria, i.e., at least a threefold $\left(\log _{2}=1.5\right)$ difference in RNA abundance with a Student $t$-test $P$ value below 0.05 , expression of the $R S c 0609$ through $R S c 0611$ genes appears to be regulated by $h r p B$ and $h r p G$ (Supplementary Table 1A). Transcription of $R S c 0612$ $\left(\log _{2}=1.4\right)$ also appears to be $h r p B$-dependent, while transcription of $R S c 0613$, which is transcribed in the opposite direction to the $R S c 0609$ through $R S c 0612$ genes (Fig. 7), is not dependent upon $h r p B$ or $h r p G$. These data also indicate that the expression ratio measured for the four genes downstream of avrA is generally smaller than the one detected for the avrA gene itself.

The monitoring of a transcriptional gene fusion created between the $R S c 0609$ gene and the $l a c Z$ reporter confirmed that $R S c 0609$ is a genuine $h r p B$-regulated gene. Although the $R S c 0609$ start codon is located 208 bp downstream of the avrA stop codon, the absence of an $h r p_{I I}$ box-related motif within this region suggested that both avrA and $R S c 0609$ could be transcribed from the same promoter. We observed that an $\mathrm{a} v r A:: \Omega$ mutation was polar on the expression of the downstream gene, since the expression of an RSc0609::lacZ fusion was abolished in an avrA mutant background, thus indicating that these two genes are comprised within the same transcription unit. Complementation experiments using plasmid pSC222, which carries the sole avrA open reading frame (ORF), proved that the HR-negative phenotype was only due to inactivation of $a v r A$ and not to a polar effect on downstream genes (data not shown). Genes RSc0609 to RSc0612 encode hypothetical products of unknown function; except for avrA, this gene block is, in fact, only conserved in one other microorganism, Thiobacillus denitrificans, an obligate chemolithoautotrophic bacterium.

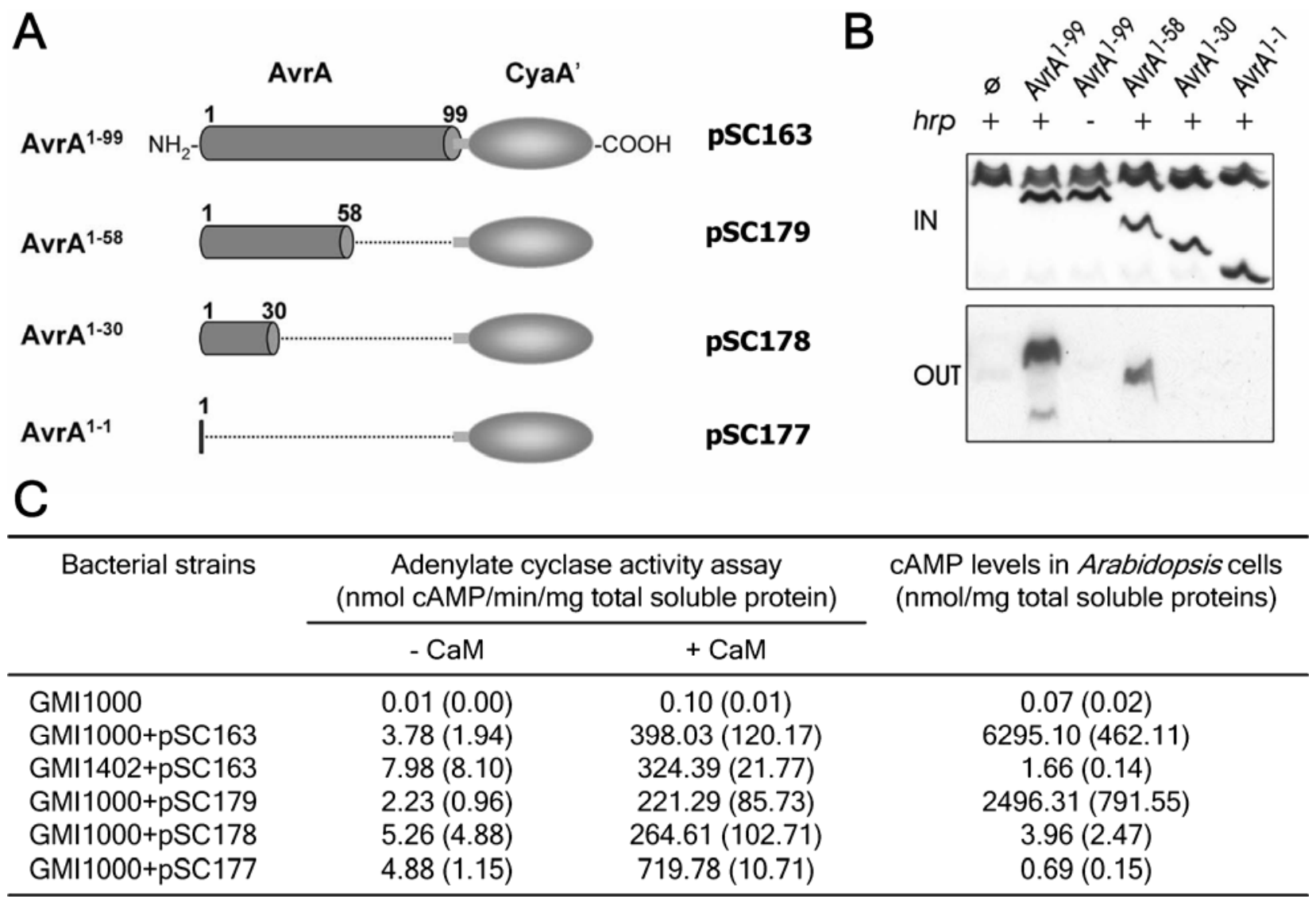

Fig. 6. Mapping of AvrA signals required for translocation of AvrA' proteins fused to the CyaA' domain. A, Schematic representation of the set of genetic constructs used in these experiments. Name of the fusion protein, a drawing of the domain composition, and the name of the plasmid that encodes this fusion are reported from left to right. Amino acid positions are given relative to the predicted first methionine of AvrA. B, In vitro secretion of AvrA'-CyaA' proteins. Top panel (IN), proteins detected in the cellular fractions. Bottom panel (OUT), proteins detected in the concentrated supernatants. The distances of migration of the specific bands are congruent with their predicted molecular masses: AvrA ${ }^{1-99}, 54 \mathrm{kDa}$; AvrA ${ }^{1-58}, 49 \mathrm{kDa}$; AvrA ${ }^{1-30}, 46 \mathrm{kDa}$; AvrA ${ }^{1-1}, 43 \mathrm{kDa}$. Gel lanes are labeled with the name of the corresponding hybrid protein expressed in the GMI1000 ( $\left.h r p^{+}\right)$or the GMI1402 ( $\left.h r p^{-}\right)$strain. Control experiments that detected the intracellular LacI protein indicated that cellular lysis could not account for the observed band patterns. C, Adenylate cyclase activity of AvrA'-CyaA' fusion proteins. On the left, in vitro adenylate cyclase activity of Ralstonia solanacearum cellular lysates with and without exogenous calmodulin (CaM) in the wild-type strain GMI1000 and in the hrp secretion mutant strain GMI1402. On the right, measurements of cyclic AMP (cAMP) detected in Arabidopsis thaliana cells after 7 h of coculture with derivatives of strains GMI1000 and GMI1402. Each measurement has three replications that are averaged, with standard deviation in brackets. 
The hypervariable region of $A v r A$ results from the insertion of variable numbers of tandem repeats (VNTR).

DNA hybridization experiments performed by Carney and Denny (1990) at the time of the identification of the avrA locus in strain AW1 suggested that this gene is widely conserved in the $R$. solanacearum species. Accordingly, the avrA locus was found in the genome sequence draft of two $R$. solanacearum strains, Molk2 (race 2 strain, isolated from banana) and UW551 (race 3 strain, isolated from potato) differing from GMI1000 (race 1 strain, wide host range) both phylogenetically and by their limited host range. Sequence analysis indicated that the $a v r A-R S c 0612$ operon is remarkably well conserved in the three strains ( 88 to $93 \%$ identity over $4 \mathrm{~kb}$ at the DNA level), the level of identity being higher between strains UW551 and Molk2, which is in agreement with the phylogenetic relationship of the three strains (Fegan and Prior 2005). The group of six genes (avrA-Rsc0613) appears to be an evolutionary conserved chromosomal block surrounded by variable genes and, except in GMI1000, associated with transposable elements (Fig. 7). In strain UW551, an insertion sequence (IS) element is found within the $a v r A$ gene promoter, just $18 \mathrm{bp}$ upstream from the start codon, thus suggesting that the gene is either not driven by its own promoter or not expressed. In order to test this hypothesis, Western blot analyses were conducted to detect the production of AvrA in concentrated culture supernatant of bacterial cells grown in a T3SS-inducing minimal medium. This was done using a polyclonal antibody raised against the AvrA $_{\mathrm{GMI} 1000}$ protein. These experiments established that AvrA is detected in the supernatant of strains GMI1000 and Molk2 but also UW551 (Fig. 8), indicating that the directly upstream IS element did not prevent transcription of the gene. Due to VNTR insertions, the AvrA protein is slightly larger in size in the other tested strains than in GMI1000, in agreement with the predicted molecular masses $\left(25.7 \mathrm{kDa}\right.$ for AvrA $\mathrm{GMI}_{1000}$ to 32.6 $\mathrm{kDa}$ for AvrA $\mathrm{A}_{\mathrm{Molk} 2}$ ).

Allelic variation was predominantly observed within the avrA effector coding sequence. In fact, this variation is mainly concentrated within a specific region in the $5^{\prime}$ part of the gene, located between nucleotides 133 and 146 downstream from the start codon in GMI1000. In strains AW1, Molk2, and UW551, this region contains VNTR, each composed of $12 \mathrm{bp}$, that lead to expansion of the $a v r A$ gene from 60 to $168 \mathrm{bp}$ as compared with GMI1000 (Fig. 9A). The strain Molk2 harbors 15 repeats, which can be distinguished in three types based on the repeat structure (Fig. 9B). Strains UW551 and AW1 possess 10 and 6 repeats, respectively, whereas, in GMI1000, the sequence CCAGCTCACCTCGCAGC between nucleotides 134 and 150 , flanked by direct repeats (underlined), can be viewed as the initial target sequence.

\section{Insertions of VNTR in avrA occur within a region required for the HR-eliciting activity of $\operatorname{AvrA}_{\text {GMI1000 }}$.}

In certain pathogenic prokaryotes, alterations at repeated stretches of DNA are used as elements of rapid genomic or phenotypic changes (Moxon et al. 1994). We noticed that the two strains carrying the most important number of VNTR in the variable region were unable to elicit the HR on tobacco; both strains UW551 and Molk2 were scored HR negative at 24 and $48 \mathrm{~h}$ postinfiltration at the rate of $10^{7} \mathrm{CFU} / \mathrm{ml}$, whereas GMI1000 is scored HR positive in the same conditions (data not shown). Therefore, we decided to investigate the role of the region of $a v r A_{G M I 1000}$ subjected to VNTR insertions in the triggering of the plant HR. We generated two Nterminal deletion constructs, named AvrA ${ }^{32-e n d}$ (pMP26) and

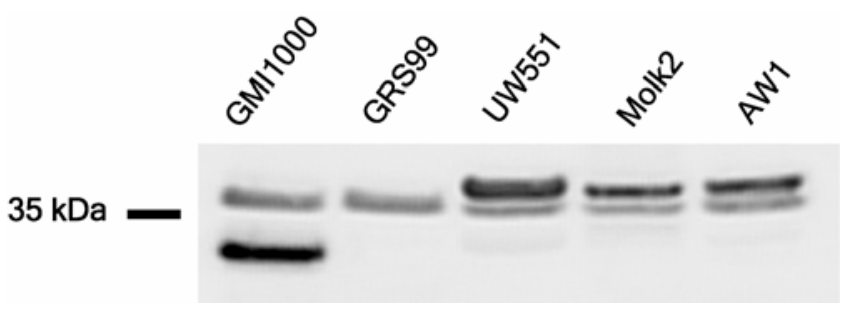

Fig. 8. Detection of AvrA in the supernatant of strains GMI1000, UW551, Molk2, and AW1. AvrA proteins are detected in concentrated supernatants by the $\mathrm{AvrA}_{\mathrm{GML} 1000}$ antibody. AvrA migrates as a $32-\mathrm{kDa}$ protein in the GMI1000 supernatant and as a 36-kDa protein in the UW551, Molk2, and AW1 supernatants. The avrA mutant strain GRS99 is used as a negative control.

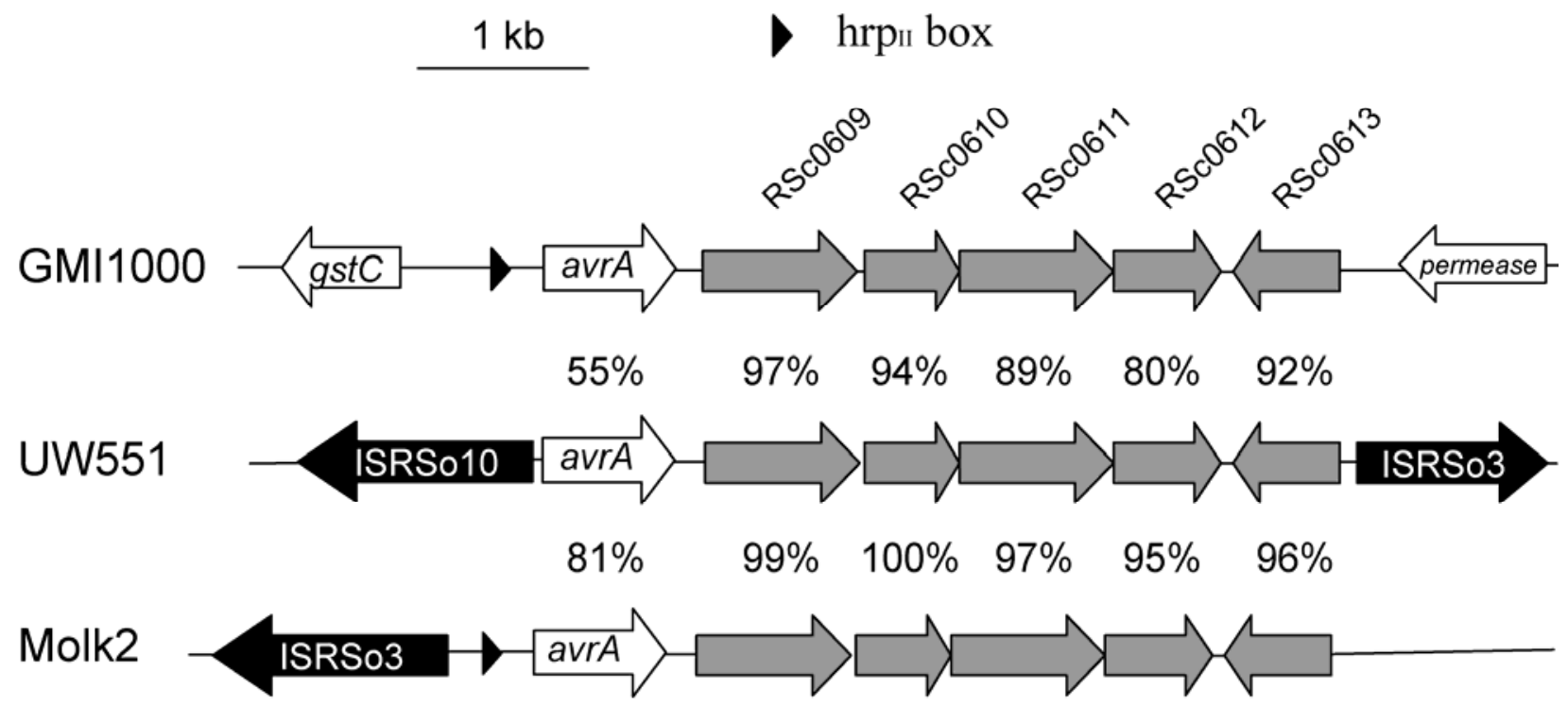

Fig. 7. Physical map of the avrA locus region in strains GMI1000, UW551, and Molk2. Genes are symbolized by arrows defining the transcription orientation. Gray-filled arrows correspond to genes encoding conserved hypothetical proteins of unknown function, and black-filled arrows to insertion sequence elements. The $h r p_{I_{I}}$ box ( $h r p B$-responsive element) is represented by a black triangle. The level of protein identity between each strain is indicated as a percentage between each homologous gene. 
$\operatorname{AvrA}^{50-\text { end }}$ (pMP28), corresponding to the AvrA $\mathrm{GMI}_{\mathrm{G} 1000}$ ORF deleted of the first 31 and 49 codons, respectively. These constructs were expressed in N. benthamiana using the Agrobacterium-mediated transient expression assay. We observed that construct $\mathrm{AvrA}^{32 \text {-end }}$ was able to trigger a HR 48 to $72 \mathrm{~h}$ postinoculation, although the plant response was slightly delayed (12 to $24 \mathrm{~h}$ ) compared with what is obtained with the full-length AvrA $\mathrm{AMI}_{\mathrm{GM} 000}$ construct (Fig. 10). In contrast, no response was observed after leaf infiltration of $A$. tumefaciens carrying $\operatorname{AvrA}^{50 \text {-end }}$ at 2 days postinoculation. Western blot analysis using the AvrA antibody demonstrated that the $A v r A^{32-e n d}$ and $\mathrm{AvrA}^{50-\text { end }}$ fusion proteins were produced in comparable amounts in plant tissues, thus indicating that the differential HR response was not due to a difference in protein stability or degradation in the plant. These results show that the 18-amino acid sequence region between positions 32 to 50 in $\mathrm{AvrA}_{\mathrm{GMI} 1000}$ is important for the HR-inducing activity of the protein; interestingly, the insertions of the 12-bp tandem repeats in $a v r A_{U W 51}$ and $a v r A_{M o l k 2}$ both occur in this region, between the codons 45 and 49 in the $a v r A_{G M I I 000}$ sequence.

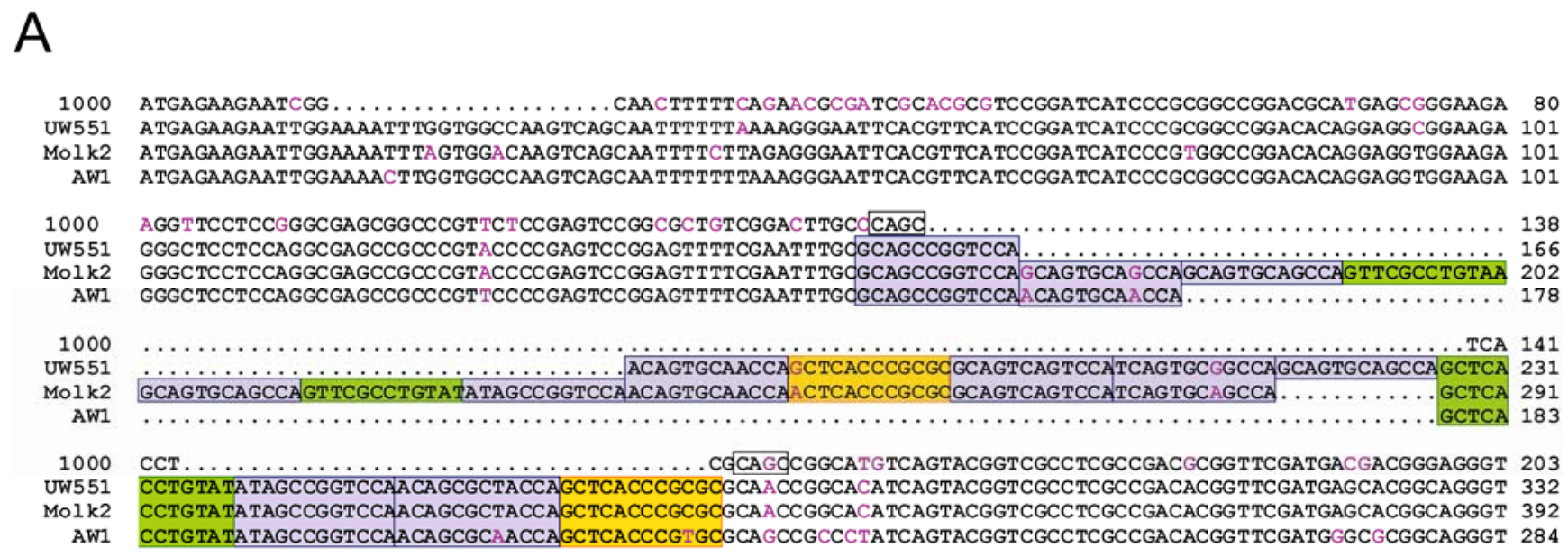

B

Type 1 repeats
\begin{tabular}{|l|}
\hline GCAGCCGGTCCA \\
GCAGTGCAGCCA \\
GCAGTGCAGCCA \\
GCAGTGCAGCCA \\
ATAGCCGGTCCA \\
ACAGTGCAACCA \\
GCAGTCAGTCCA \\
TCAGTGCAGCCA \\
ATAGCCGGTCCA \\
ACAGCGCTACCA \\
\hline
\end{tabular}

\begin{tabular}{|l|l|}
\hline Type 2 repeats & Type 3 repeats \\
\hline GTTCGCCTGTAA & ACTCACCCGCGC \\
GTTCGCCTGTAT & GCTCACCCGCGC \\
\hline
\end{tabular}

Fig. 9. Structure of the hypervariable $5^{\prime}$ region of $a v r A$, which carries variable numbers of tandem repeats (VNTR). A, Nucleotide sequence alignment of the $5^{\prime}$ end of the $a v r A$ gene (starting from the ATG start codon) in strains GMI1000 (1000), UW551 (RRSL_01581, National Center for Biotechnology Information (NCBI) accession EAP71870), Molk2 (RSMKO4490, NCBI accession CAQ56934), and AW1 (NCBI accession AAS01725). Conserved nucleotides are in black while variable ones are in purple. Dots correspond to absent nucleotides. Colored boxes identify the VNTR, each color defining a distinct class of VNTR. B, Alignment of the three classes of VNTR within $a v r A_{M o l k 2}$, showing the nucleotide conservation of the repeats.
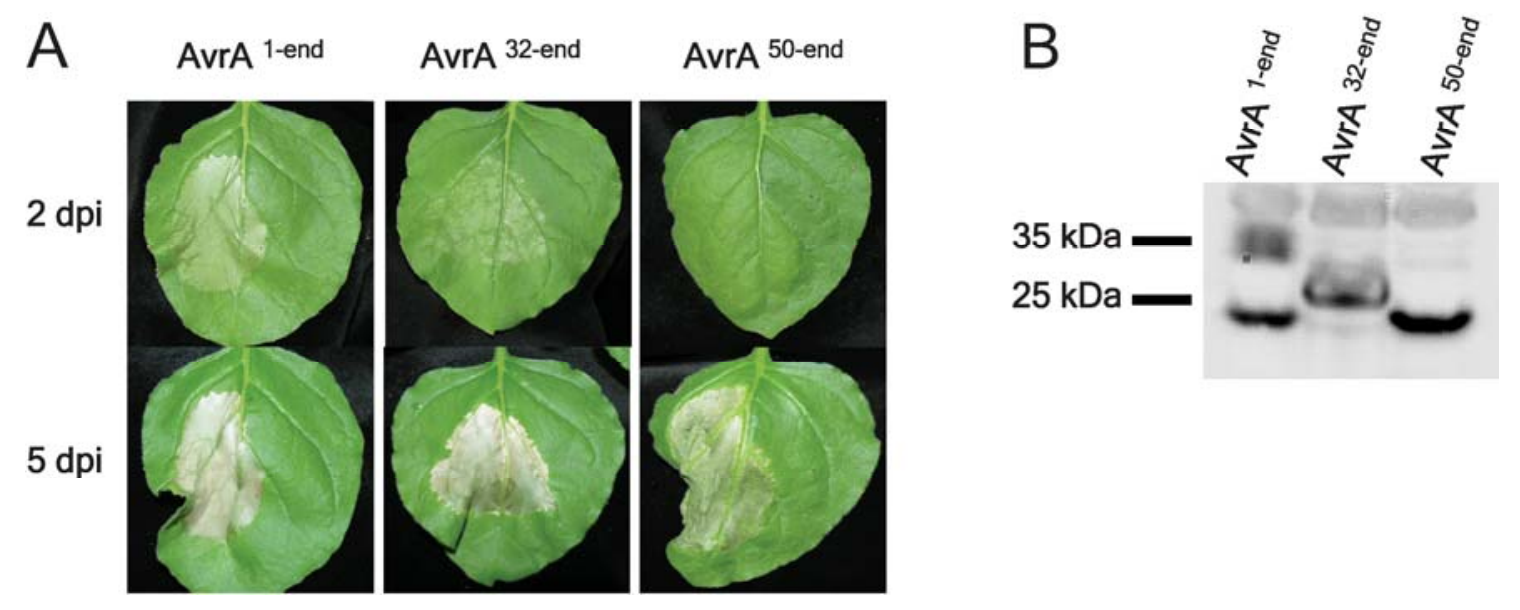

Fig. 10. Identification of an 18-amino acid domain in the N-terminal part of AvrA $\mathrm{GMI}_{\mathrm{G} 1000}$ required for hypersensitive response (HR) elicitation. A, HR elicitation induced by the transient expression of $a v r A^{32-e n d}$ and $a v r A^{50-e n d}$ on Nicotiana benthamiana. Leaves were infiltrated with the Agrobacterium tumefaciens strains carrying the pMP25 (AvrA $\left.{ }^{1-\text { end }}\right)$, pMP26 (AvrA ${ }^{32-e n d}$ ), and pMP28 (AvrA ${ }^{50-\text { end }}$ ) plasmids. Pictures were taken 2 and 5 days after infiltration. B, Detection of the AvrA ${ }^{1-e n d}, A_{r} A^{32-e n d}$, and AvrA ${ }^{50-e n d}$ proteins from N. benthamiana leaf tissues (2 days postinoculation), by Western blotting using the $\mathrm{AvrA}_{\mathrm{GMI} 1000}$ antibody. Two products were detected using the $\mathrm{AvrA}^{1-\mathrm{end}}$ construct, the smaller one resulting from a probable processing in planta. 


\section{DISCUSSION}

Two GMI1000 T3SS effectors control host specificity toward tobacco species.

We identified two effector genes from strain GMI1000, avrA and popPl, that both act as HR elicitors on several Nicotiana species and that specifically restrict the host range of the strain on tobacco. AvrA was first identified in strain AW1 and was shown to determine incompatibility of that strain on $\mathrm{N}$. $\mathrm{ta}$ bacum (Carney and Denny 1990). However, disruption of the avrA gene was not sufficient to restore full pathogenicity of the strain (Carney and Denny 1990; Robertson et al. 2004). In this study, we show that in addition to AvrA, PopP1 triggers plant defense reactions that are sufficient to protect the plants from GMI1000 infection, since acquisition of pathogenicity on tobacco is observed only in the avrA popPl background. This finding supports the view that type III effectors play a critical role in the delineation of nonhost interaction profiles of bacterial pathogens. Another recent example of such behavior is illustrated by a P. syringae pv. tomato DC3000 mutant deleted for hopQ1-1 that extended the ability of the strain to cause disease on the nonhost $N$. benthamiana (Wei et al. 2007).

PopP1 is a type III effector secreted by the T3SS that belongs to the YopJ/AvrRxv family of cysteine protease effectors (Lavie et al. 2002). PopP1 was previously characterized as an avirulence determinant toward various lines of another solanaceous host, petunia. It was shown to control host specificity in a plant genotype-dependent pattern and the popP1 mutant strain became pathogenic on the petunia line that is resistant to the wild-type strain (Lavie et al. 2002). It has been established that popP1 is present in most Asiatic and African isolates (phylotypes I and III) but is absent from American isolates such as Molk2 or UW551 (phylotype II) (Lavie et al. 2004). This probably explains why most of the isolates that are pathogenic on tobacco, such as K60, are of American (phylotype II) origin since, in the absence of popP1 in these strains, a single mutation event in avrA is predicted to restore virulence if the strain possesses the functions required to wilt tobacco.

AvrA and PopP1 both participate to promote HR elicitation on the three Nicotiana species studied here. HR elicitation is indeed completely abolished in the avrA popPl mutant strain while the simple mutants display at least a partial HR activity. The recognition of PopP1 appears to vary, ranging from a strong HR response ( $N$. glutinosa) to reduced or delayed responses ( $N$. tabacum, $N$. benthamiana). In $N$. tabacum and $N$. benthamiana, the AvrA-dependent HR is more strongly and rapidly induced than the PopP1-dependent HR; similar observations on differential kinetics of $\mathrm{HR}$ induction were also reported in the case of the P. syringae avrRpml- and avrRpt2dependent HR on Arabidopsis (Ritter and Dangl 1996). In N. glutinosa, Agrobacterium-mediated expression experiments show that AvrA is sufficient to induce an HR response (Fig. 5C), but AvrA is superimposed in GMI1000 by PopP1, thus explaining why the avrA mutant still elicits a wild-type HR on this tobacco species (Fig. 3B and C). These results suggest that several Nicotiana species contain resistance genes that encode $\mathrm{R}$ proteins able to recognize the presence of AvrA and PopP1 inside plant cells. Because an AvrA::EGFP fusion localizes in the cytoplasm of Arabidopsis protoplasts (unpublished results), the recognition of AvrA itself or of its activity is expected to occur in the cytoplasm of plant cells.

Any role of avrA and popPI in $R$. solanacearum virulence remains unknown, since no impaired virulence could be observed with either the avrA or popPl simple mutants when inoculated by standard root inoculation on tomato and on the compatible Arabidopsis ecotype Col-0 (Cunnac et al. 2004). This situation was, in fact, encountered for the large majority of GMI1000 type III effector mutants on these host plants, probably because of a functional overlap among the large effector repertoire (Poueymiro and Genin 2009) or specific roles on other hosts.

\section{avrA, a T3SS-effector gene that belongs}

to an operon conserved within the $R$. solanacearum species.

avrA encodes a 230-amino acid protein that does not present any homology to other proteins in the databases except for the orthologous gene product found in other $R$. solanacearum strains (Gabriel et al. 2006; Robertson et al. 2004). avrA ${ }_{G M I 1000}$ is located on the $R$. solanacearum chromosome, and its promoter region contains a typical $h r p B$-responsive element, the $h r p_{I I}$ box, $70 \mathrm{bp}$ upstream of the start codon. We provide genetic evidence that avrA is the first ORF of an operon with the downstream gene $R S c 0609$. Two observations support the view that the avrA operon comprises five genes (avrA-Rsc0609 to avrA-RSc0612): i) no intergenic region is predicted between the ORF Rsc0609 and RSc0612, and ii) expression data indicate that four genes downstream of avrA are $h r p B$-regulated, suggesting that their expression is driven by the $\operatorname{rrp}_{I I}$ box-containing avrA promoter. The finding that avrA belongs to a polycistronic operon is intriguing because the four downstream genes do not appear to encode T3SS effectors. RSc0609 and $R S c 0610$ harbor typical lipoprotein and peptide signal sequences, respectively, $R S c 0612$ is predicted to encode a transmembrane protein, and the $R S c 0611$ product belongs to the ApbE family of proteins that function in metal cofactor assembly (Skrovan and Downs 2003). In contrast to AvrA, none of the products encoded by the downstream ORF are predicted to carry $\mathrm{N}$-terminal T3SS-export signals. It would be interesting to determine whether these downstream genes are involved in some posttranslational modifications of AvrA.

Another uncommon aspect of this operon is the existence of a long-transcribed but noncoding region between $a v r A$ and $R S c 0609$ (208 bp). A similar situation is also found in GMI1000 in two other atypical operons, the $h r p B$ operon (150 bp between $h r p B$ and the $h r c C$ secretin gene; Genin et al. 1992) and the $h r p Y$ operon (193 bp between the $h r p Y$ pilin subunit gene and hrpZ; Cunnac et al. 2004). We hypothesize that these long intergenic regions within operons may be a means to modulate transcription levels between the upstream and downstream genes.

The avrA operon structure appears to be widely conserved within the $R$. solanacearum species since it is found in taxonomically distant strains such as GMI1000 (phylotype I, Asian origin) and Molk2 / UW551 (phylotype II, American origin) (Fegan and Prior 2005), suggesting that this gene block has an ancestral evolutionary origin. Comparative genomic hybridization confirmed this hypothesis, since the avrA operon was found to be present in more than 15 strains representative of the four described phylotypes within the species (Guidot et al. 2007).

\section{Translocation of AvrA into plant cells through the T3SS.}

The Agrobacterium-mediated transient expression of AvrA into the leaf cells of three tobacco species ( $N$. tabacum, $N$. benthamiana, and N. glutinosa) induced a necrotic response, indicating that AvrA requires delivery to the plant cell to exert its HR-eliciting activity. Using the CyaA' translocation reporter system, we also provide the biochemical evidence that AvrA carries functional T3SS-dependent export signals that enable this protein to traffic through the Hrp pathway to reach the plant cell cytoplasm. We have initiated the characterization of AvrA translocation signals by deletion mapping and found that the first 58 codons are sufficient for directing efficient secretion in extracellular minimal medium and injection into Arabi- 
dopsis cells. Previous work showed that the first 28 codons of $X$. campestris pv. vesicatoria AvrBs2 are sufficient for secretion (Mudgett et al. 2000), while injection requires at least the first 41 codons but was significantly enhanced with the first 58 codons (Casper-Lindley et al. 2002). Similarly, the first 10 codons of Pseudomonas syringae pv. tomato AvrPto were necessary for $h r p$-mediated secretion in culture and, although the 16 first codons could direct a weak translocation into plant cell, the first 50 codons were considerably more efficient (Schechter et al. 2004). Thus, AvrA translocation signals are located in a region similar in length to those of effectors from other phytopathogenic bacteria.

Beside hrc genes, the $R$. solanacearum hrp cluster contains a number of genes with counterparts only in the Xanthomonas genus. Here, we addressed the role in AvrA translocation on tobacco of four of these genes that were hypothesized to be auxiliary proteins of the T3SS (Van Gijsegem et al. 2002). The competence of the mutants tested in this study to translocate the AvrA-CyaA' fusion correlated with their ability to trigger HR as previously reported (Van Gijsegem et al. 2002). However, it is surprising to notice that the virulence of the hrpJ mutant on tomato is only mildly affected, while our results show that it is almost unable to inject the AvrA ${ }^{1-99}-\mathrm{CyaA}^{\prime}$ fusion protein. Possible explanations to this result are that the role of $\mathrm{HrpJ}$ in translocation of type III effectors is plant species specific or, alternatively, that it is involved in injection of only a subset of type III effectors including AvrA.

\section{The avrA gene is the target of 12-bp tandem repeat insertion tracts.}

Nucleotide sequence of the $a v r A$ gene from different strains revealed that the $5^{\prime}$ part of the gene contains a hypervariable region that is the result of VNTR insertions. VNTR occur within the $\mathrm{N}$-terminal region required for the translocation of $\mathrm{AvrA}_{\mathrm{GMI} 1000}$ into plant cells, but there is evidence that VNTR do not prevent the secretion of $\mathrm{AvrA}_{\mathrm{Uw551}}$ or $\mathrm{Avr} \mathrm{A}_{\mathrm{Molk} 2}$ through the T3SS (Fig. 8). We observe that these VNTR insertions mainly result in enrichment in serine residues, and abundance of serine is one of the more prominent features of the GMI1000 type III effector export pattern (Cunnac et al. 2004), so the N-terminal domains of AvrA $\mathrm{Uw}_{\mathrm{Uw} 51}$ or AvrA $\mathrm{A}_{\mathrm{Molk2}}$ also display typical T3SS effector features.

In this study, we show that the 18-amino acid region (between residues 32 to 50) in which the VNTR insertion occurs is a domain required for full HR elicitation. However, a delayed HR can still be elicited with the AvrA ${ }^{50-e n d}$ construct, indicating that this 18-amino acid region is not the sole domain able to trigger HR. Mutation or deletion of an avirulence determinant is a means for a pathogen to escape the plant surveillance system (Leach and White 1996). VNTR are polymorphic minisatellites that have been documented in several microorganisms as elements of rapid genomic or phenotypic changes (Metzgar and Wills 2000; Moxon et al. 1994). Our data suggest that VNTR insertions within avrA might impact HR elicitation, but since the 12-bp insertions do not disrupt the avrA reading frame, it is possible that the insertions do not lead to a complete loss of function of the gene. This could be a way to preserve a role for AvrA in the disease process or a means to a rapid and potentially reversible inactivation of an avirulence gene.

The $a v r A$ gene appears to be a frequent target of transposable elements. In several HR-negative strains from the United States, avrA was shown to be disrupted by two miniature inverted-repeat transposable elements (MITE) after nucleotides 461,542 , or 575 (Robertson et al. 2004). It is also notable that a transposable element is present in the avrA gene promoter in strain UW551; our data show that the gene in this case is still expressed, but its regulation is probably constitutive and $h r p B$ - independent, since the IS insertion occurs in between the $h r p_{I I}$ box and the avrA start codon. The reason for this deregulated expression is unclear but suggests that the control of the expression of this effector gene might also be critical for function. In summary, it is remarkable that $a v r A$, which is a widely conserved gene in the species, appears to be subjected to various DNA insertions or mobile elements (MITE, IS, VNTR) that could result in a better adaptability of the pathogen. These genetic insertions in the avrA locus probably allow $R$. solanacearum to evade the recognition and defense response of tobacco but also allow the gene to be maintained in the population if it is required for pathogenicity on susceptible hosts. The identification of one or more of the molecular targets of AvrA within susceptible plant cells may aid in our understanding of such a role of this effector protein and its contribution to disease development. The amenability of $N$. benthamiana to powerful virus-induced gene silencing technology may also provide valuable insights on the identity of the signaling pathways mediating AvrA-dependent plant responses.

\section{MATERIALS AND METHODS}

\section{Bacterial strains, plasmids, growth conditions, and plant material.}

The bacterial strains and plasmids used for this study are described in Table 1. Escherichia coli and Agrobacterium tumefaciens cells were grown in Luria-Bertani (LB) medium at 37 and $28^{\circ} \mathrm{C}$, respectively. $R$. solanacearum was grown in complete medium B or minimal medium (MM) at $28^{\circ} \mathrm{C}$ (Boucher et al. 1987). Antibiotics were used at the following concentrations (mg/liter): ampicillin, 50; kanamycin, 25; gentamycin $(\mathrm{Gm}), 10$ or 20; spectinomycin $(\mathrm{Spc}), 40$; tetracycline, 10; rifampicin, 50; chloramphenicol, 25; carbenicillin, 25. The plants used in this study were Nicotiana tabacum cv. Bottom special, $N$. glutinosa, and $N$. benthamiana.

\section{DNA manipulations for genetic constructs.}

Standard methods were used (Ausubel et al. 1990) unless otherwise stated. Plasmids pMP25, pMP26, pMP28, pMP103, and pPR45 used in this study were constructed by Gateway technology (Invitrogen, Carlsbad, CA, U.S.A.), following the instructions of the manufacturer. The polymerase chain reaction (PCR) products were first amplified by ORF-specific primers (Supplementary Table 2) and then by the attB1 and attB2 universal primers, except popP1, which was amplified by a one-step PCR using attB1-PopP1 and attB2-PopP1 primers. The PCR products flanked by the $a t t B$ sites were recombined into the pDONR 207 vector (Invitrogen) to create entry vectors with attL sites. The inserts cloned into entry vectors were subsequently recombined into the destination vectors.

To generate plasmids pSC163, pSC177, pSC178, and pSC179, DNA fragments that encompass the promoter and different 5 '-end portions of the $a v r A$ ORF were PCR amplified and cloned in the pSC154 reporter vector, to give serial constructions consisting of an initiation codon, the first 30,58, and 99 codons of $a v r A$, followed by a BglII restriction site and codons 2 to 400 of the original cyaA' gene (Sory and Cornelis 1994). These constructs were subsequently inserted in pLAFR6 for autonomous replication in $R$. solanacearum.

\section{Construction of an avrA-popP1 double mutant strain.}

In order to screen for the identification of other GMI1000 T3SS effectors involved in HR elicitation on $N$. tabacum besides AvrA, genomic DNA from an avrA mutant strain was extracted and used to transform, as described by Cunnac and associates (2004), a collection of approximately 70 T3SS effector mutant strains described elsewhere (Cunnac et al. 2004; Lavie et al. 
2002; Occhialini et al. 2005). For each mutant, two individual transformants were checked for their ability to induce a HR on $N$. tabacum at an infiltration concentration of $10^{8} \mathrm{CFU} / \mathrm{ml}$ after 24 h. Strain GRS473 carries a double disruption of the avrA gene by an $\Omega\left(\mathrm{Gm}^{\mathrm{r}}\right)$ cassette from strain GRS99 (Cunnac et al. 2004) and of the popPl gene by an $\Omega\left(\mathrm{Spc}^{\mathrm{r}}\right)$ cassette from strain GMI1658 (Lavie et al. 2002). The structure of the deleted loci was checked by Southern blot analysis.

Complementation analyses were made by introducing plasmids pSC222 (pLAFR6::avrA) and pGMI3623 (pLAFR6:: popP1) into GRS99 and GRS473, respectively. Complementa- tion was scored by the restoration of the HR-inducing ability of the resulting strains on $N$. tabacum (avrA) or $N$. glutinosa (popPl).

\section{Plant tests.}

To test for HR, bacterial suspensions at $10^{7}$ and $10^{8} \mathrm{CFU} / \mathrm{ml}$ were infiltrated into leaves of 4-week-old Nicotiana plants with a 1-ml needleless syringe as described previously (Boucher et al. 1987). Pathogenicity assays were performed by watering 4-week-old $N$. benthamiana and $N$. glutinosa transplants and 2-week-old $N$. tabacum transplants with $50 \mathrm{ml}(70$

Table 1. Bacterial strains and plasmids used in this study

\begin{tabular}{|c|c|c|}
\hline Strain or plasmid & Relevant genotype or characteristics ${ }^{a}$ & References \\
\hline \multicolumn{3}{|l|}{ Strains } \\
\hline Escherichia coli $\mathrm{DH} 5 \alpha$ & $\mathrm{F}^{-}$recA lacZDM15 & Bethesda Research Laboratory \\
\hline \multicolumn{3}{|l|}{ Ralstonia solanacearum } \\
\hline K60 & Wild-type strain & Kelman and Person 1961 \\
\hline GMI1000 & Wild-type strain & Boucher et al. 1987 \\
\hline GMI1402 & Tn5-B20 insertion in $h r c S$ & Van Gijsegem et al. 1995 \\
\hline GMI1410 & Tn5-B20 insertion in hrpY & Van Gijsegem et al. 1995 \\
\hline GMI1415 & Tn5-B20 insertion in hpaP & Arlat et al. 1992 \\
\hline GMI1525 & $h r p B$ mutant strain, $\mathrm{Spc}^{\mathrm{r}}$ & Genin et al. 1992 \\
\hline GMI1586 & hrpD::apha-3 mutant & Van Gijsegem et al. 2002 \\
\hline GMI1589 & hrpH::apha-3 mutant & Van Gijsegem et al. 2002 \\
\hline GMI1591 & hrpJ::apha-3 mutant & Van Gijsegem et al. 2002 \\
\hline GMI1658 & popP $1:: \Omega, \mathrm{Spc}^{\mathrm{r}}$ & Lavie et al. 2002 \\
\hline GMI1694 & $h r c V:: \Omega \mathrm{Spc}^{\mathrm{r}}$ & Cunnac et al. 2004 \\
\hline GMI1728 & GMI1000/pLAFR3::hrpB, Tc ${ }^{\mathrm{r}}$ & Occhialini et al. 2005 \\
\hline GMI1778 & hrpB hrpG double mutant & This study \\
\hline GRS099 & brg46 (RSc0608) mutant, i.e avrA:: $\Omega, \mathrm{Gm}^{\mathrm{r}}$ & Cunnac et al. 2004 \\
\hline GRS473 & popP $1:: \Omega$ avrA:: $\Omega$ double mutant, $\mathrm{Gm}^{\mathrm{r}} \mathrm{Spc}^{\mathrm{r}}$ & This study \\
\hline GRS475 & $\mathrm{RSc} 0609:: \mathrm{pCZ} 367 \mathrm{Gm}^{\mathrm{r}}$ & This study \\
\hline GRS476 & RSc0609::pCZ367 hrpB:: $\Omega, \mathrm{Gm}^{\mathrm{r}} \mathrm{Spc}^{\mathrm{r}}$ & This study \\
\hline GRS477 & 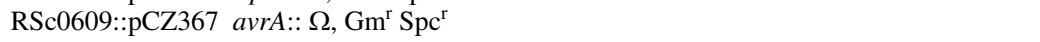 & This study \\
\hline \multicolumn{3}{|l|}{ Agrobacterium tumefaciens } \\
\hline AGL1 & $\begin{array}{l}\text { C58 chromosomal background carrying an insertion mutation in the recA gene, pTiBo542 } \\
\text { Ti plasmid, } \text { Rif }^{\mathrm{r}}, \mathrm{Cb}^{\mathrm{r}}\end{array}$ & Lazo et al. 1991 \\
\hline GV3101::pMP90 & C58 chromosomal background, pMP90 Ti plasmid, Rif ${ }^{\mathrm{r}}, \mathrm{Gm}^{\mathrm{r}}$ & Koncz and Schell 1986 \\
\hline GV3101::pMP90RK & C58 chromosomal background, pMP90RK Ti plasmid, Rif $^{\mathrm{r}}, \mathrm{Gm}^{\mathrm{r}}, \mathrm{Km}^{\mathrm{r}}$ & Koncz and Schell 1986 \\
\hline \multicolumn{3}{|l|}{ Plasmids } \\
\hline pMDC32 & Destination vector; constitutive expression vector, harboring a dual $35 \mathrm{~S}$ promoter, $\mathrm{Km}^{\mathrm{r}}$ & Curtis and Grossniklaus 2003 \\
\hline pTH19 & $\begin{array}{l}\text { Destination vector adapted from pET15-b (Novagen, Madison, WI, U.S.A.), N-terminal } \\
\text { His }_{6} \text {, T7 promoter, Amp }\end{array}$ & Daenke et al. 2008 \\
\hline pAM-PAT-P35S-GW-CFP & $\begin{array}{l}\text { Destination vector; constitutive expression vector, harboring a dual } 35 \mathrm{~S} \text { promoter and used } \\
\text { for the construction of C-terminal CFP fusion, } \mathrm{Cb}^{\mathrm{r}}\end{array}$ & Bernoux et al. 2008 \\
\hline pLAFR6 & pLAFR1 with $\operatorname{trp}$ terminators, $\mathrm{Tc}^{\mathrm{r}}$ & $\begin{array}{l}\text { B. Staskawicz (University } \\
\text { of California Berkeley) }\end{array}$ \\
\hline pBBL12 & pLAFR6 with a $1.5-\mathrm{kb}$ fragment carrying $h r p G$ & Brito et al. 1999 \\
\hline pCZ367 & pUC18-derived vector used for insertional mutagenesis, $\mathrm{Ap}^{\mathrm{r}} \mathrm{Gm}^{\mathrm{r}}$ & Cunnac et al. 2004 \\
\hline pSC154 & pET-26b(+)-derived vector with the $c y a A^{\prime}$ gene used for translational fusion constructs, $\mathrm{Km}^{\mathrm{r}}$ & Cunnac et al. 2004 \\
\hline pPR45 & $\begin{array}{l}\text { pXCSG-Strep (Witte et al. 2004)-derived plasmid that contains the GALA6 gene (Angot et } \\
\text { al. 2006) }\end{array}$ & P. Remigi (LIPM France) \\
\hline pGMI3623 & pLAFR6 carrying a 2.08-kb HindIII-KpnI fragment containing the popPl gene & Lavie et al. 2002 \\
\hline pMP25 & $\begin{array}{l}\text { pMDC32-derived plasmid that contains the full-length avrA gene, amplified with primers } \\
\text { avrA-START and avrA-STOP }\end{array}$ & This study \\
\hline pMP26 & $\begin{array}{l}\text { pMDC32-derived plasmid that contains the truncated avrA gene from the } 32 \text { nd codon to } \\
\text { the stop codon, amplified with primers avrA-32 and avrA-STOP }\end{array}$ & This study \\
\hline pMP28 & $\begin{array}{l}\text { pMDC32-derived plasmid that contains the truncated avrA gene from the 50th codon to the } \\
\text { stop codon, amplified with primers avrA-50 and avrA-STOP }\end{array}$ & This study \\
\hline pMP103 & $\begin{array}{l}\text { pAM-PAT-P35S-GW-CFP-derived plasmid that contains the popP1 gene, amplified with } \\
\text { primers AttB1-PopP1 and AttB2-PopP1 }\end{array}$ & This study \\
\hline pSC163 & $\begin{array}{l}\text { pLAFR6-derived plasmid that contains a polymerse chain reaction (PCR) fragment } \\
\text { corresponding to } a v r A^{1-99} \text {, amplified with primers AvrA1 and AvrA2 and fused to cyaA' }\end{array}$ & This study \\
\hline pSC177 & $\begin{array}{l}\text { pLAFR6-derived plasmid that contains a PCR fragment corresponding to } a v r A^{1-1} \\
\text { amplified with primers AvrA } 1 \text { and AvrA5 and fused to cyaA }\end{array}$ & This study \\
\hline pSC178 & $\begin{array}{l}\text { pLAFR6-derived plasmid that contains a PCR fragment corresponding to } a v r A^{1-30} \text {, } \\
\text { amplified with primers AvrA } 1 \text { and AvrA6 and fused to cyaA' }\end{array}$ & This study \\
\hline pSC179 & $\begin{array}{l}\text { pLAFR6-derived plasmid that contains a PCR fragment corresponding to avrA } A^{1-58} \text {, } \\
\text { amplified with primers AvrA1 and AvrA7 and fused to cyaA }{ }^{\prime}\end{array}$ & This study \\
\hline pSC222 & $\begin{array}{l}\text { pLAFR6 containing the avrA gene on a 967-bp PCR fragment amplified with primers } \\
\text { AvrA-CplF and AvrA-CplR }\end{array}$ & This study \\
\hline
\end{tabular}

${ }^{\text {a }} \mathrm{Spc}^{\mathrm{r}}, \mathrm{Tc}^{\mathrm{r}}, \mathrm{Gm}^{\mathrm{r}}, \mathrm{Rif}^{\mathrm{r}}, \mathrm{Cb}^{\mathrm{r}}, \mathrm{Km}^{\mathrm{r}}$, and $\mathrm{Amp}^{\mathrm{r}}$, = resistant to spectinomycin, tetracycline, gentamycin, rifampicin, carbenicillin, kanamycin, and ampicillin. 
$\mathrm{ml}$ for $N$. tabacum) of a suspension containing $10^{8}$ cells per milliliter. Assays were made with 10 plants for each bacterial strain and were repeated three times. The plants were incubated in a growth chamber at $28^{\circ} \mathrm{C}(16 \mathrm{~h}$ of light, $8 \mathrm{~h}$ of dark). Disease development was scored daily, using a disease-index scale ranging from 0 to 4 , according to the percentage of wilted leaves $(0=$ no wilt, $1=1$ to $25 \%, 2=26$ to $50 \%, 3=51$ to $75 \%, 4=>75 \%)$.

Production of $\boldsymbol{R}$. solanacearum concentrated supernatants.

To test the secretion of AvrA in GMI1000, GRS99, IPO1609, Molk2, and AW1 strains, the bacteria were grown in minimal medium supplemented with $10 \mathrm{mM}$ glutamate, 10 $\mathrm{mM}$ sucrose, and $100 \mu \mathrm{g}$ of Congo Red per milliliter, to reach an optical density at $600 \mathrm{~nm}\left(\mathrm{OD}_{600}\right)$ of approximately 1.0. After centrifugation $(4,000 \mathrm{rpm}, 10 \mathrm{~min}), 1 \mathrm{ml}$ of supernatant was filter-sterilized through a $0.45-\mu \mathrm{m}$ syringe filter and was precipitated overnight on ice by adding $1 \mathrm{ml}$ of a cold $25 \%$ trichloroacetic acid solution. After centrifugation $(13,000 \mathrm{rpm}$, $\left.15 \mathrm{~min}, 4^{\circ} \mathrm{C}\right)$, the supernatant was washed twice with a cold $10 \%$ acetone solution and was dried at room temperature. The pellet was resuspended in Laemmli buffer and was analyzed by sodium dodecyl sulfate-polyacrylamide gel electrophoresis (SDS-PAGE) electrophoresis and immunoblotting.

\section{A. tumefaciens-mediated expression of proteins in plant cells.}

Tobacco leaves were infiltrated with A. tumefaciens GV3101::pMP90 containing pMP25, pMP26, or pMP28 (a CaMV 2x35S::avrA construct) or with A. tumefaciens GV3101:: pMP90RK containing pMP103 (a CaMV 2x35S::popP1-CFP fusion) or pPR45 (a CaMV 2x35S:GALA6-strep fusion). Agrobacteria were grown overnight in LB medium containing appropriate antibiotic selections. Cells were pelleted at 4,000 rpm, were resuspended in infiltration medium (10 $\mathrm{mM} \mathrm{MgCl}, 10$ $\mathrm{mM}$ morpholineethanesulfonic acid, and $150 \mu \mathrm{M}$ acetosyringone), and were incubated for $2 \mathrm{~h}$ at room temperature. Resuspended cells were infiltrated into leaves of 4-week-old Nicotiana plants at an $\mathrm{OD}_{600}=0.4$ with a $1-\mathrm{ml}$ needleless syringe . The infiltrated plants were incubated in growth chambers for a 16 -h day at $20^{\circ} \mathrm{C}$. After infiltration $(48 \mathrm{~h})$, three disks $(7 \mathrm{~mm})$ of Nicotiana benthamiana leaves expressing the proteins of interest were homogenized in Laemmli buffer, in order to be analyzed by Western blotting.

\section{Production of an AvrA GMI1000 $_{\text {antibody. }}$}

The $a v r A_{G M I 1000}$ gene was cloned into expression vector pTH19 (Daenke et al. 2008), which provides an N-terminal His6 tag. Recombinant AvrA protein was produced in E. coli BL21 (DE3) cells as an insoluble protein after induction with $1 \mathrm{mM}$ isopropyl- $\beta$-D-thiogalactoside. Cells were lysed by sonication in $50 \mathrm{mM}$ Tris $\mathrm{HCl}$, pH 7.4, $150 \mathrm{mM} \mathrm{NaCl}, 0.1 \mathrm{mg}$ of lysozyme per milliliter of protease inhibitor cocktail (complete; Roche, Branchburg, NJ, U.S.A.). After centrifugation, the pellet was solubilized with $8 \mathrm{M}$ urea. The lysate was loaded onto a NiNTA column (Qiagen, Basel, Switzerland) preequilibrated with $50 \mathrm{mM}$ Tris $\mathrm{HCl}$, pH 7.4, $250 \mathrm{mM} \mathrm{NaCl}$, $6 \mathrm{M}$ urea, and $5 \mathrm{mM}$ imidazol. After washing with $10 \mathrm{mM}$ imidazol, AvrA was eluted with $250 \mathrm{mM}$ imidazole. Fractions containing the eluted protein were pooled and dialyzed in 50 $\mathrm{mM}$ Tris $\mathrm{HCl}, \mathrm{pH} 7.4,250 \mathrm{mM} \mathrm{NaCl}, 6 \mathrm{M}$ urea, and $10 \%$ glycerol. This preparation was used to immunize rabbits.

\section{AvrA detection by Western blotting.}

Immunodetection of AvrA proteins was performed by loading the samples on SDS-PAGE gels (NuPAGE 4 to $12 \%$ bis-tris gel; Invitrogen). Proteins were transferred to Protran BA85 nitrocellulose transfer membranes (Whatman, Dassel, Germany). AvrA proteins were detected using a 1/3,000 dilution ratio of the $\mathrm{AvrA}_{\mathrm{GMI} 1000}$ rabbit polyclonal antibody. Goat antirabbit antibody conjugated with horseradish peroxidase was used as secondary antibody (Santa Cruz Biotechnology, Santa Cruz, CA, U.S.A.) and was detected by using the chemiluminescent HRP substrate (Immobilon Western, Millipore, Bedford, MA, U.S.A.).

\section{Gene expression studies.}

For transcriptome analysis, the $R$. solanacearum wholegenome DNA microarray was used (Occhialini et al. 2005). RNA extraction, probe labeling, microarray hybridization, signal quantification, and data analysis were performed as explained elsewhere (Occhialini et al. 2005). RNAs were extracted from cultures grown to $\mathrm{OD}_{600}=0.8$ in $\mathrm{MM}$ and the GMI1000 strain was always used as a reference condition. For each experimental condition, at least two RNA preparations from independent cultures were used, and a minimum of four hybridizations were performed, swapping dye labeling. Levels of significance were determined by a $P$ value $<0.05$ in Student's $t$ test.

The RSc0609-lacZ fusion was created as previously described (Cunnac et al. 2004), using the insertion plasmid pCZ367 in which an internal fragment of the gene was cloned after PCR amplification using primers $4832 \mathrm{Xb}$ and $4832 \mathrm{Hin}$. $\beta$-galactosidase assays were performed as described previously (Lavie et al. 2002).

\section{CyaA'-based translocation assays.}

The procedures for the adenylate cyclase assay were previously described in Schechter and associates (2004) and Cunnac and associates (2004). Briefly, strain GMI1000 and derivatives carrying plasmids were cocultivated with Arabidopsis thaliana cells or infiltrated into $N$. tabacum leaves. Samples were harvested $7 \mathrm{~h}$ later, were transferred into Eppendorf tubes, and were immediately frozen in liquid nitrogen. For cAMP extraction, samples in Eppendorf tubes were kept frozen while grinding by shaking with 2-mm tungsten beads in a Qiagen Mixer Mill MM300 for two runs of $2 \mathrm{~min}$ at $30 \mathrm{~Hz}$. Samples were stored at $-80^{\circ} \mathrm{C}$ before cAMP quantification. Protein concentration was assessed with the Bio-Rad (Munich, Germany) protein assay kit. cAMP levels were monitored with a cAMP enzyme immunoassay kit (Biotrak; Amersham Pharmacia Biotech, Uppsala, Sweden), according to the manufacturer's instructions.

To test the secretion of the AvrA-CyaA' fusion proteins, cellular fractions and concentrated supernatants were produced as described (Cunnac et al. 2004). Immunodetection of CyaA' fusion proteins was performed using a monoclonal mouse antiserum against adenylate cyclase (courtesy of N. Guiso, Institut Pasteur, Paris) as described by Cunnac and associates (2004).

\section{ACKNOWLEDGMENTS}

We are very grateful to $\mathrm{C}$. Baud for help with antibody production, $\mathrm{P}$. Remigi for providing plasmid pPR45, J.-L. Pariente, S. Bosc, and C. Icher for plant preparation. This work was supported by ANR-05-BLAN 017001 and by grants from the Ministère de l'Enseignement Supérieur et de la Recherche to M. Poueymiro and S. Cunnac.

\section{LITERATURE CITED}

Angot, A., Peeters, N., Lechner, E., Vailleau, F., Baud, C., Gentzbittel, L., Sartorel, E., Genschik, P., Boucher, C., and Genin, S. 2006. Ralstonia solanacearum requires F-box-like domain-containing type III effectors to promote disease on several host plants. Proc. Natl. Acad. Sci. U.S.A. 103:14620-14625. 
Arlat, M., Gough, C. L., Zischek, C., Barberis, P. A., Trigalet, A., and Boucher, C. A. 1992. Transcriptional organization and expression of the large hrp gene cluster of Pseudomonas solanacearum. Mol. PlantMicrobe Interact. 5:187-193.

Ausubel, F. M., Brent, R., Kingston, R. E., Moore, D. D., Seidman, J. G., Smith, J. A., and Struhl, K. 1990. Current Protocols in Molecular Biology. Green Publishing Associates and Wiley Interscience, New York.

Bernoux, M., Timmers, T., Jauneau, A., Brière, C., de Wit, P. J., Marco, Y., and Deslandes, L. 2008. RD19, an Arabidopsis cysteine protease required for RRS1-R-mediated resistance, is relocalized to the nucleus by the Ralstonia solanacearum PopP2 effector. Plant Cell 20:2252-2264.

Block, A., Li, G., Fu, Z.Q., and Alfano, J. R. 2008. Phytopathogen type III effector weaponry and their plant targets. Curr. Opin. Plant Biol. 11:396-403.

Boucher, C. A., Van Gijsegem, F., Barberis, P. A., Arlat, M., and Zischek, C. 1987. Pseudomonas solanacearum genes controlling both pathogenicity on tomato and hypersensitivity on tobacco are clustered. J. Bacteriol. 169:5626-5632.

Brito, B., Marenda, M., Barberis, P., Boucher, C., and Genin, S. 1999 $p r h J$ and $h r p G$, two new components of the plant-dependent regulatory cascade controlled by PrhA in Ralstonia solanacearum. Mol. Microbiol. 31:237-251.

Carney, B. F., and Denny, T. P. 1990. A cloned avirulence gene from Pseudomonas solanacearum determines incompatibility on Nicotiana tabacum at the host species level. J. Bacteriol. 172:4836-4843.

Casper-Lindley, C., Dahlbeck, D., Clark, E. T., and Staskawicz, B. J. 2002. Direct biochemical evidence for type III secretion-dependent translocation of the AvrBs2 effector protein into plant cells. Proc. Natl. Acad. Sci. U.S.A. 99:8336-8341.

Cunnac, S., Occhialini, A., Barberis, P., Boucher, C., and Genin, S. 2004 Inventory and functional analysis of the large Hrp regulon in Ralstonia solanacearum: Identification of novel effector proteins translocated to plant host cells through the type III secretion system. Mol. Microbiol. 53:115-128

Curtis, M. D., and Grossniklaus, U. 2003. A gateway cloning vector set for high-throughput functional analysis of genes in planta. Plant Physiol. 133:462-469.

Daenke, S., Jones, E. Y., and Stuart D. I. 2008. European structural proteomics - a perspective. Pages 463-504 in: Structural Proteomics and Its Impact on the Life Sciences. J. L. Sussman and I. Silman, eds. World Scientific Publishing Co., Pte Ltd., Singapore.

Dangl, J. L., Ritter, C., Gibbon, M. J., Mur, L. A., Wood, J. R., Goss, S., Mansfield, J., Taylor, J. D., and Vivian, A. 1992. Functional homologs of the Arabidopsis RPM1 disease resistance gene in bean and pea. Plant Cell 4:1359-1369.

Deslandes, L., Olivier, J., Peeters, N., Feng, D. X., Khounlotham, M., Boucher, C., Somssich, I., Genin, S., and Marco, Y. 2003. Physical interaction between RRS1-R, a protein conferring resistance to bacterial wilt, and PopP2, a type III effector targeted to the plant nucleus. Proc. Natl. Acad. Sci. U.S.A. 100:8024-8029.

de Wit, P. J. 2007. How plants recognize pathogens and defend themselves. Cell Mol. Life Sci. 64:2726-2732.

Fegan, M., and Prior, P. 2005. How complex is the 'Ralstonia solanacearum species complex'. Pages 449-462 in: Bacterial wilt Disease and the Ralstonia solanacearum Species Complex. C. Allen, P. Prior, and A. C. Hayward, ed. APS Press, St. Paul, MN, U.S.A.

Flor, H. H. 1955. Host-parasite interaction in flax rust-its genetics and other implications. Phytopathology 45:680-685.

Gabriel, D. W., Allen, C., Schell, M., Denny, T. P., Greenberg, J. T., Duan, Y. P., Flores-Cruz, Z., Huang, Q., Clifford, J. M., Presting, G., González, E. T., Reddy, J., Elphinstone, J., Swanson, J., Yao, J., Mulholland, V., Liu, L., Farmerie, W., Patnaikuni, M., Balogh, B., Norman, D., Alvarez, A., Castillo, J. A., Jones, J., Saddler, G., Walunas, T., Zhukov, A., and Mikhailova, N. 2006. Identification of open reading frames unique to a select agent: Ralstonia solanacearum race 3 biovar 2. Mol. PlantMicrobe Interact. 19:69-79.

Genin, S., Gough, C. L., Zischek, C., and Boucher, C. A. 1992. Evidence that the $\operatorname{hrpB}$ gene encodes a positive regulator of pathogenicity genes from Pseudomonas solanacearum. Mol Microbiol 6:3065-3076.

Genin, S., and Boucher, C. 2004. Lessons learned from the genome analysis of Ralstonia solanacearum. Annu. Rev. Phytopathol. 42:107-134

Grant, S. R., Fischer, E. J., Chang J. H., Mole, B. M., and Dangl, J. L. 2006. Subterfuge and manipulation: Type III effector proteins of phytopathogenic bacteria. Annu. Rev. Microbiol. 60:425-49.

Guidot, A., Prior, P., Schoenfeld, J., Carrère, S., Genin, S., and Boucher, C. 2007. Genomic structure and phylogeny of the plant pathogen Ralstonia solanacearum inferred from gene distribution analysis. J. Bacteriol. 189:377-387.

Hayward, A. C. 1991. Biology and epidemiology of bacterial wilt caused by Pseudomonas solanacearum. Annu. Rev. Phytopathol. 29:65-87.
Jones, J. D., and Dangl, J. L. 2006. The plant immune system. Nature 444:323-329

Kearney, B., and Staskawicz, B. J. 1990. Widespread distribution and fitness contribution of Xanthomonas campestris avirulence gene avrBs2. Nature 346:385-386.

Kelman, A., and Person, L. H. 1961. Strains of Pseudomonas solanacearum differing in pathogenicity to tobacco and peanut. Phytopathology $51: 158-161$.

Klement, Z. 1963. Method for the rapid detection of pathogenicity of phytopathogenic pseudomonads. Nature 199:299-300.

Koncz, C., and Schell, J. 1986. The promoter of the $\mathrm{T}_{\mathrm{L}}$-DNA gene 5 controls the tissue-specific expression of chimeric genes carried by a novel type of Agrobacterium binary vector. Mol. Gen. Genet. 204:383-396.

Lavie, M., Seunes, B., Prior, P., and Boucher, C. 2004. Distribution and sequence analysis of a family of type Ill-dependent effectors correlate with the phylogeny of Ralstonia solanacearum strains. Mol. PlantMicrobe Interact. 17:931-940.

Lavie, M., Shillington, E., Eguiluz, C., Grimsley, N., and Boucher, C. 2002. PopP1, a new member of the YopJ/AvrRxv family of type III effector proteins, acts as a host-specificity factor and modulates aggressiveness of Ralstonia solanacearum. Mol. Plant-Microbe Interact. 15:1058-1068.

Lazo, G. R., Stein, P. A., and Ludwig, R. A. 1991. A DNA transformationcompetent Arabidopsis genomic library in Agrobacterium. Biotechnology 9:963-967.

Leach, J. E., and White, F. F. 1996. Bacterial avirulence genes. Annu. Rev. Phytopathol. 34:153-179.

Lim, M. T., and Kunkel, B. N. 2005. The Pseudomonas syringae avrRpt2 gene contributes to virulence on tomato. Mol. Plant-Microbe Interact. 18:626-633.

Lorang J. M., Shen H., Kobayashi D., Cooksey D., and Keen N. T. 1994. avrA and avrE in Pseudomonas syringae pv. tomato PT23 play a role in virulence on tomato plants. Mol. Plant-Microbe Interact. 7:508-515.

Losada, L., Sussan, T., Pak, K., Zeyad, S., Rozenbaum, I., and Hutcheson, S. W. 2004. Identification of a novel Pseudomonas syringae Psy61 effector with virulence and avirulence functions by a HrpL-dependent promoter-trap assay. Mol. Plant-Microbe Interact. 17:254-262.

Metzgar, D., and Wills, C. 2000. Evolutionary changes in mutation rates and spectra and their influence on the adaptation of pathogens. Microbes Infect. 2:1513-1522.

Moxon, E. R., Rainey, P. B., Nowak, M. A., and Lenski, R. E. 1994. Adaptive evolution of highly mutable loci in pathogenic bacteria. Curr. Biol. 4:24-33.

Mudgett, M. B., Chesnokova, O., Dahlbeck, D., Clark, E. T., Rossier, O., Bonas, U., and Staskawicz, B. J. 2000. Molecular signals required for type III secretion and translocation of the Xanthomonas campestris AvrBs2 protein to pepper plants. Proc. Natl. Acad. Sci. U.S.A. 97:13324-13329.

Mur, L. A., Kenton, P., Lloyd, A. J., Ougham, H., and Prats, E. 2008. The hypersensitive response: The centenary is upon us but how much do we know? J. Exp. Bot. 59:501-520.

Occhialini, A., Cunnac, S., Reymond, N., Genin, S., and Boucher, C. 2005. Genome-wide analysis of gene expression in Ralstonia solanacearum reveals that the $h r p B$ gene acts as a regulatory switch controlling multiple virulence pathways. Mol. Plant-Microbe-Interact. 18:938-949.

Poueymiro, M., and Genin, S. 2009. Secreted proteins from Ralstonia solanacearum: A hundred tricks to kill a plant. Curr. Opin. Microbiol. $12: 44-52$

Ritter, C., and Dangl, J. L. 1995. The avrRpml gene of Pseudomonas syringae pv. maculicola is required for virulence on Arabidopsis. Mol. Plant-Microbe Interact. 8:444-453.

Ritter, C., and Dangl, J. L. 1996. Interference between two specific pathogen recognition events mediated by distinct plant disease resistance genes. Plant Cell 8:251-257.

Robertson, A. E., Wechter, W. P., Denny, T. P., Fortnum, B. A, and Kluepfel, D. A. 2004. Relationship between avirulence gene (avrA) diversity in Ralstonia solanacearum and bacterial wilt incidence. Mol. Plant-Microbe Interact. 17:1376-1384.

Roden, J., Eardley, L., Hotson, A., Cao, Y., and Mudgett, M. B. 2004. Characterization of the Xanthomonas AvrXv4 effector, a SUMO protease translocated into plant cells. Mol. Plant-Microbe Interact. 17:633643.

Salanoubat, M., Genin, S., Artiguenave, F., Gouzy, J., Mangenot, S., Arlat, M., Billault, A., Brottier, P., Camus, J. C., Cattolico, L., Chandler, M., Choisne, N., Claudel-Renard, C., Cunnac, S., Demange, N., Gaspin, C., Lavie, M., Moisan, A., Robert, C., Saurin, W., Schiex, T., Siguier, P., Thebault, P., Whalen, M., Wincker, P., Levy, M., Weissenbach, J., and Boucher, C. A. 2002. Genome sequence of the plant pathogen Ralstonia solanacearum. Nature 415:497-502.

Schechter, L. M., Roberts, K. A., Jamir, Y., Alfano, J. R., and Collmer, A. 
2004. Pseudomonas syringae type III secretion system targeting signals and novel effectors studied with a Cya translocation reporter. J. Bacteriol. 186:543-555.

Skovran, E., and Downs, D. M. 2003. Lack of the ApbC or ApbE protein results in a defect in Fe-S cluster metabolism in Salmonella enterica serovar Typhimurium. J. Bacteriol. 185:98-106.

Sory, M. P., and Cornelis, G. R. 1994. Translocation of a hybrid YopE-adenylate cyclase from Yersinia enterocolitica into HeLa cells. Mol. Microbiol. 14:583-594.

Swarup, S., Yang, Y., Kingsley, M. T., and Gabriel, D. W. 1992. An Xanthomonas citri pathogenicity gene, pthA, pleiotropically encodes gratuitous avirulence on nonhosts. Mol. Plant-Microbe Interact. 5:204-213.

Tronchet, M., Ranty, B., Marco, Y., and Roby, D. 2001. HSR203 antisense suppression in tobacco accelerates development of hypersensitive cell death. Plant J. 27:115-127.

Valls, M., Genin, S., and Boucher, C. 2006. Integrated regulation of the type III secretion system and other virulence determinants in Ralstonia solanacearum. PLoS Pathog. 2:e82. Published online.

Van Gijsegem, F., Gough, C., Zischek, C., Niqueux, E., Arlat, M., Genin, S., Barberis, P., German, S., Castello, P., and Boucher, C. 1995. The hrp gene locus of Pseudomonas solanacearum, which controls the produc- tion of a type III secretion system, encodes eight proteins related to components of the bacterial flagellar biogenesis complex. Mol. Microbiol. 15:1095-1114.

Van Gijsegem, F., Vasse, J., De Rycke, R., Castello, P., and Boucher, C. 2002. Genetic dissection of Ralstonia solanacearum hrp gene cluster reveals that the $\mathrm{HrpV}$ and $\mathrm{HrpX}$ proteins are required for Hrp pilus assembly. Mol. Microbiol. 44:935-946.

Wei, C. F., Kvitko, B. H., Shimizu, R., Crabill, E., Alfano, J. R., Lin, N. C., Martin, G. B., Huang, H. C., and Collmer, A. 2007. A Pseudomonas syringae pv. tomato DC3000 mutant lacking the type III effector HopQ1-1 is able to cause disease in the model plant Nicotiana benthamiana. Plant J. 51:32-46.

Whalen, M. C., Innes, R. W., Bent, A. F., and Staskawicz, B. J. 1991. Identification of Pseudomonas syringae pathogens of Arabidopsis and a bacterial locus determining avirulence on both Arabidopsis and soybean. Plant Cell 3:49-59.

Witte, C. P., Noel, L. D., Gielbert, J., Parker, J. E., and Romeis, T. 2004. Rapid one-step protein purification from plant material using the eightamino acid StrepII epitope. Plant Mol. Biol. 55:135-147.

Zhou, J. M., and Chai, J. 2008. Plant pathogenic type III effectors subdue host responses. Curr. Opin. Microbiol. 11:179-185. 